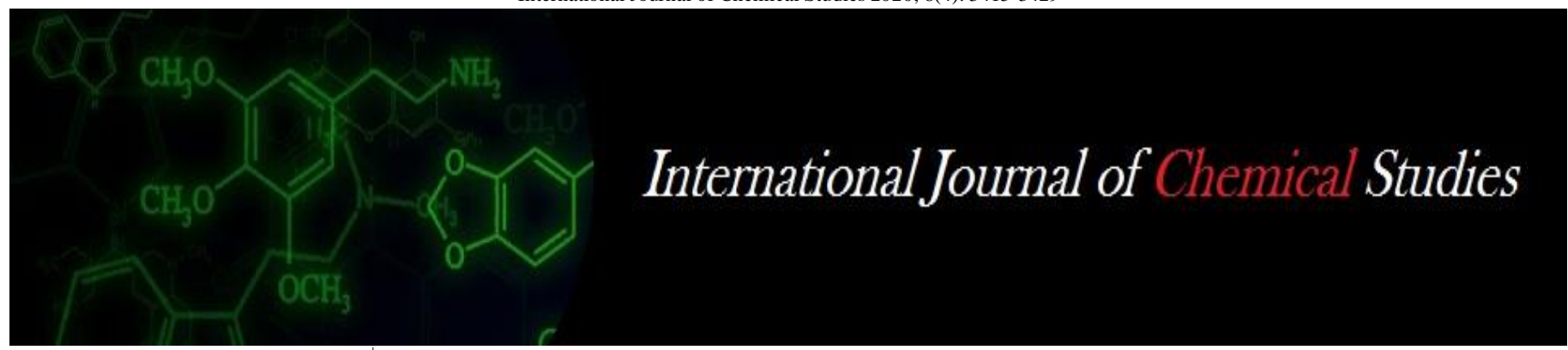

P-ISSN: 2349-8528

E-ISSN: 2321-4902

www.chemijournal.com

IJCS 2020; 8(4): 3415-3429

(C) 2020 IJCS

Received: 10-05-2020

Accepted: 12-06-2020

Savan Donga

Department of Biosciences (UGC-CAS), Saurashtra

University, Rajkot, Gujarat,

India

Sumitra Chanda

Department of Biosciences

(UGC-CAS), Saurashtra

University, Rajkot, Gujarat,

India

Corresponding Author: Sumitra Chanda

Department of Biosciences

(UGC-CAS), Saurashtra

University, Rajkot, Gujarat,

India

\section{Evaluation of phytochemical profile and antioxidant activity of some medicinal plants seed extracts obtained by traditional and modern (green) extraction methods}

\section{Savan Donga and Sumitra Chanda}

DOI: $\underline{\text { https://doi.org/10.22271/chemi.2020.v8.i4aq.10183 }}$

\begin{abstract}
The medicinal plants have been one of the major sources of medicines since the beginning of civilization. There is high demand for plant based medicines, nutraceuticals and cosmeceuticals all across the globe. Herbal medicines are becoming more and more popular in recent years with their over increasing acceptability in both developing and developed countries. All parts of the plant leaf, stem, bark, root, flowers, fruits, seeds, peels, are therapeutically useful. But flowers, seeds and peels are less utilized. Seeds are generally thrown into environment and these waste disposal has become a critical global problem. But they have a rich source of many valuable bioactive compounds especially phenols and flavonoids because of which they can be used therapeutically. In the present work, 6 plant seeds viz. Annona squamosa L., Carica papaya Linn. (Un-ripe), Carica papaya Linn. (Ripe), Ceiba pentandra L. Gaertn., Trachyspermum ammi L. and Trigonella foenum - graecum L. were screened for their phytochemical profile and antioxidant efficacy using different extraction techniques. The seeds were extracted by different extraction methods viz. Traditional methods -decoction, maceration and Modern methods - microwave assisted extraction and ultrasonic assisted extraction. The phytochemicals or bioactive components evaluated were total phenols, phenolic acids, flavonoids, flavonols and proanthocyanidin content. In vitro antioxidant activity in terms of 2, 2-diphenyl-1-picrylhydrazyl (DPPH) free radical scavenging activity, Superoxide anion free radical (O2-) scavenging activity, 2, 2'-Azino-bis(3-ethyl) benzothiazoline-6-sulfonic acid (ABTS) radical cation scavenging activity and Ferric reducing antioxidant power (FRAP) was evaluated. All the extracts showed varied levels of phytochemical and antioxidant activity. But the best activity was shown by modern methods especially UAE. Thus, seeds can be profitably, beneficially employed as a rich source of bioactive compounds which can be effectively utilized as a source of natural antioxidant and reduce environmental pollution.
\end{abstract}

Keywords: Seed extracts, extraction techniques, phytochemicals, antioxidant activity

\section{Introduction}

Plants are essential part of human civilization. Medicinal plants are relied upon by over $80 \%$ of the world population for their necessary health care requirements mainly because they are comparatively cheap, widely easily available and they are free from many side effects associated with synthetic drugs. Diverse plants have been used as a source of novel drugs either in a pure compound form or their extract form and it provided unlimited opportunities to expand a diversity of new innovative drugs (Sen et al., 2010) ${ }^{[1]}$.

In traditional Indian medicines, all parts of the plant viz. leaf, stem, bark, root, flowers, fruits, seeds, peel are recognized to have therapeutic properties and have been used to treat various diseases. Any part or rather all parts of the plant are therapeutically useful. However, it is always desirable and beneficial to make use of that part of the plant which is less utilized. For eg. flowers, seeds, peels, etc. All these parts are generally thrown into the environment and this agro or bio waste disposal is problematic economically and environmentally. Huge amount of solid wastes in the form of peels and seeds are generated by the fruit processing industries and these wastes if not disposed properly cause serious environmental problems such as water pollution, unpleasant odors, explosions and combustion, asphyxiation and greenhouse gas emissions. But they have a great potential for reuse as antimicrobials, antioxidants, anti-cancer agents, etc. (Mirabella et al., 2014; Rakholiya et al., 2014; Lee et al., 2020) ${ }^{[2,3,4]}$. 
Infectious diseases and cancer fall under some of the leading cause of deaths worldwide. Now-a-days people are suffering infections caused by multidrug resistant bacteria and fungi. Earlier antibiotic therapy came to the rescue but because of use, misuse and overuse, the antibiotics which were once working or no more able to tackle the microorganisms. Also newer ways of multi drug resistance mechanisms are evolving. Another dire problem is oxidative stress which is because of free radical generation. Free radicals are responsible for a number of diseases and disorders like cancer, atherosclerosis, cardiovascular disease, Parkinson's, liver injury and rheumatoid arthritis (Alok et al., 2014) ${ }^{[5]}$. So in order to tackle these ever green problems, newer alternative drugs are required which will have better efficacy than existing drugs, with a novel mode of action.

Seeds can be used as dietary compounds for eg Momordica charantia, Cucumis sativus, Punica granatum etc. as spices for eg. Syzygium aromaticum, Piper nigrum, Elettaria cardamomum, and essential oils can be extracted from them for eg. Pongamia pinnata oil, Mentha piperita oil, Azadirachta indica oil. But some seeds are thrown away into the environment for eg. Tamarindus indica, Annona squamosa, Ziziphus jujube, Aegle marmelos, Manilkara hexandra, etc. Seeds have various nutritional compounds and phytoconstituents, they show different activitiesy like Mesua ferrea showed antimicrobial activity (Chanda et al., 2013) ${ }^{[6]}$, Prunus persica seeds showed antioxidant activity (Loizzo et al., 2015) ${ }^{[7]}$ while Cucumis melo and Citrullus lanatus seeds showed analgesic and anti-inflammatory effects (Wahid et al., 2020). There are various phytoconstituents in them especially phenols and flavonoids which show good antioxidant activity. There is a direct correlation between phenol and flavonoid content and antioxidant activity ( $\mathrm{Vu}$ et al., 2017) ${ }^{[9]}$. It is very well known that plants with good antioxidant activity show various biological activities Pterocarpus santalinus leaf, stem and bark - antimicrobial activity (Donga et al., 2017) ${ }^{[10]}$, Cassia spectabilis leaf - antimalarial activity (Ekasari et al., 2018) ${ }^{[11]}$, Syzygium cumini leaf - antidiabetic, antioxidant and cytotoxic activities (Artanti et al., 2019) ${ }^{[12]}$, Centella asiatica - anti-inflammatory activity (Baby et al., 2020) ${ }^{[13]}$.

The phytochemical profile of the plant can give us an idea regarding its therapeutic efficacy. The next step is efficient extraction of the phytoconstituents present in them. There are many methods of extraction and they fall into two categories viz. conventional and non-conventional. The former are also known as traditional methods which include infusion, percolation, maceration, reflux extraction, Soxhlet, etc while the later are known as modern or green extraction methods which include high pressure liquid extraction, super critical $\mathrm{CO}_{2}$ extraction, accelerated solvent extraction, microwave assisted extraction, ultra sonic assisted extraction, Pulsed electric field Extraction, Enzyme assisted extraction etc (Zhang et al., 2018) ${ }^{[14]}$. There are no universal criteria and it varies from plant to plant. Both methods have advantages and disadvantages but the main aim is to use best method of extraction for phenols and flavonoids which will extract completely the phytoconstituents without losing its efficacy and with no modification of its chemical nature.

In the present work, 6 plant seeds viz. Annona squamosa L., Carica papaya Linn. (Un-ripe), Carica papaya Linn. (Ripe), Ceiba pentandra L. Gaertn., Trachyspermum ammi L. and Trigonella foenum - graecum L (Figure) were screened for their phytochemical profile and antioxidant efficacy using different extraction techniques. The extraction was done using two traditional methods viz. decoction (DCE) and maceration (MCE) and two modern methods viz. microwave assisted extraction (MAE) and ultrasonic assisted extraction (UAE). Annona squamosa L., belongs to Annonaceae family. The seed showed antioxidant and antimicrobial activity (Kothari and Seshadri, 2010; Gupta et al., 2019) ${ }^{[15,16]}$. Carica papaya Linn. belongs to Cariccaceae family. The seed and latex showed molluscicidal activity (Jaiswal and Singh, 2008) ${ }^{[17]}$ while peel and seed showed antioxidant activity (Ang et al., 2012) [18]. Ceiba pentandra L. Gaertn., belongs to Bombacaceae family. The seed showed antioxidant activity (Loganayaki et al., 2013) ${ }^{[19]}$ while seed oil showed antiinflammatory activity (Ravi Kiran et al., 2014) ${ }^{[20] .}$ Trachyspermum ammi L. belongs to Apiaceae family. The seeds showed anticancer and anticandidal activity (Ramya et al., 2017; Wahab et al., 2020) [21, 22]. Trigonella foenum graecum L belongs to Fabaceae family. The seeds showed antioxidant and antimicrobial (Norziah et al., 2015) ${ }^{[23]}$ and antiasthmatic activity (Jain et al., 2020) ${ }^{[24]}$.

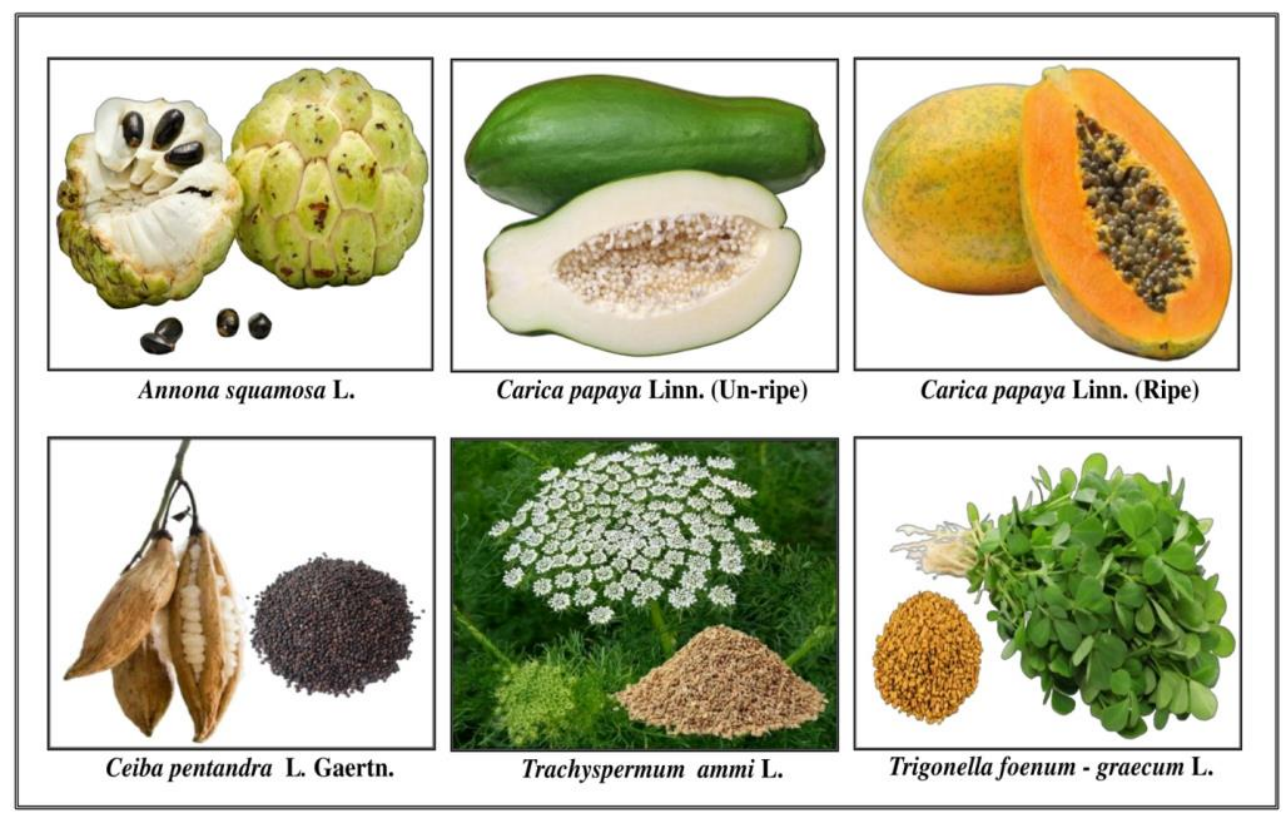

Fig 1: Photographs of screened plant seeds 
Considering the above, the aim of the present work was evaluation of phytochemical profile and antioxidant activity of some medicinal plants seed extracts obtained by traditional and modern (green) extraction methods.

\section{Materials and methods \\ Plant collection}

Trachyspermum ammi L. and Trigonella foenum - graecum $\mathrm{L}$ were purchased from local market in Rajkot, Gujarat, India while fruits of Annona squamosa L., Carica papaya Linn. (Un-ripe), Carica papaya Linn. (Ripe), Ceiba pentandra L. Gaertn., were collected in Rajkot, Gujarat, India. Seeds were separated from fruit, washed with tap water followed by distilled water. The washed seeds were dried under shade. All seeds were crushed to fine powder and stored in air tight closed containers for further studies.

\section{Extraction}

The extraction was done using two traditional methods viz. decoction (DCE) and maceration (MCE) (Vongsak et al., 2013) ${ }^{[25]}$ and two modern methods viz. microwave assisted extraction (MAE) (Dahmoune et al., 2015) ${ }^{[26]}$ and ultrasonic assisted extraction (UAE) (Chen et al., 2007) ${ }^{[27]}$. The procedure followed is as described by Yoganandi et al., $(2018)^{[28]}$.

\section{Quantitative phytochemical analysis and antioxidant activity.}

The total phenol content (TPC) was determined according to the modified method of Mc Donald et al. (2001) ${ }^{[29]}$ by using Folin-Ciocalteu's reagent method. The total phenol content was expressed in terms of gallic acid equivalent (GAE) $(\mathrm{mg} / \mathrm{g}$ of extracted compound). The phenolic acid content (PAC) of different extracts of $L$. bipinnata leaf was determined according to the modified method of Tomczyk et al. (2010) [30] by using Arnov's reagent method. The phenolic acid content was expressed in terms of caffeic acid equivalent (mg /g of extracted compound). The amount of total flavonoid content (TFC) was determined according to the modified method of Boutennoun et al., (2017) ${ }^{[31]}$ by using Aluminium chloride $\left(\mathrm{AlCL}_{3}\right)$ colorimetric method. The total flavonoid content was expressed in terms of quercetin equivalent $(\mathrm{mg} / \mathrm{g}$ of extracted compound). The content of flavonols was determined by modified colorimetric method described by Boutennoun et al., (2017) ${ }^{[31]}$ and Abdel-Hameed (2009) ${ }^{[32]}$. The results are expressed in terms of quercetin equivalent (mg/g of extracted compound). The proanthocyanidin content was determined by the butanol- $\mathrm{HCl}$ assay as described by Zilic et al. (2011) ${ }^{[33]}$. The proanthocyanidins content was expressed in terms of leucocyanidin equivalent $(\mathrm{mg} / \mathrm{g}$ of extracted compound). All samples were analyzed in triplicate and mean values are presented with \pm S. E. M (Standard Error of Mean). The procedure followed is as described by Yoganandi et al., (2018) ${ }^{[28]}$. The antioxidant activity was evaluated by four different in vitro antioxidant assays viz. 2, 2-diphenyl-1-picrylhydrazyl (DPPH) free radical scavenging activity (McCune and Johns, 2002) ${ }^{[34]}$, Superoxide anion free radical $\left(\mathrm{O}_{2}^{-}\right)$scavenging activity (Robak and Gryglewski, 1988) [35], 2, 2'-Azino-bis-(3-ethyl) benzothiazoline-6sulfonic acid (ABTS) radical cation scavenging activity (Re $e t$ al., 1999) ${ }^{[36]}$ and Ferric reducing antioxidant power (FRAP) (Benzie and Strain, 1996) ${ }^{[37]}$. The procedure followed is as described by Kaneria et al., (2018) ${ }^{[38]}$.

\section{Results and discussion \\ Extractive yield}

The extractive yield of all 6 plant seeds is given in Fig. 1. The extractive yield was different in different plant seeds; the traditional and modern techniques affected different plant seeds differently. It varied from plant to plant. The trend of extractive yield in different plant seeds was as follows: $A$. squamosa - UAE > DCE > MAE > MCE; $C$. papaya un-ripe $\mathrm{MAE}>\mathrm{UAE}>\mathrm{MCE}>\mathrm{DCE} ; C$. papaya ripe $-\mathrm{MAE}>\mathrm{UAE}$ $>\mathrm{DCE}>\mathrm{MCE}$; $C$. pentandra $-\mathrm{UAE}=\mathrm{MCE}=\mathrm{DCE}>\mathrm{MAE}$; T. ammi - UAE > MAE > MCE > DCE; $T$. foenum - graecum - MAE > MCE > UAE > DCE. When extractive yield of plant seeds was compared, both the modern techniques MAE and UAE gave maximum extractive yield. In almost all the plant seeds, the traditional techniques DCE or MCE gave lowest extractive yield except in $C$. pentandra. It can be stated that extraction techniques definitely affected the extractive yield in different plant seeds. Maximum extractive yield in all the plant seeds was in the range $15.7 \%$ to $31.5 \%$ (Fig. 1). Highest extractive yield was in 9 min MAE extract of $T$. foenum graecum (Fig.1E). Minimum extractive yield in all the plant seeds was in the range $3 \%$ to $17.4 \%$. Lowest extractive yield was in MCE extract of C. papaya ripe seed (Fig. 1C). Maximum extractive yield in A. squamosa, was in 9 min ultra sonicated extracted $(26.7 \%)$; in $C$. papaya un-ripe seed, it was in 9 min microwaves exposed extract (30.6\%); in $C$. papaya ripe seed, it was in $6 \mathrm{~min}$ microwaves exposed extract $(18.4 \%)$; in $C$. pentandra, it was in 6 min ultra sonicated extracted $(15.7 \%)$; in T. ammi, it was in 6 min ultra sonicated extracted $(28.4 \%)$ and in $T$. foenum - graecum, it was in 9 min microwaves exposed extract $(31.5 \%)$. When all the 6 plant seeds were compared, maximum extractive yield was in T. foenum - graecum plant seed and minimum in C. papaya ripe seed (Figs. 1E and1C).

It is very well reported in the literature that extraction method, extraction conditions and extraction solvents directly influence extractive yield and extractability of bioactive compounds or phytoconstituents (Taddeo et al., 2016; de Oliveira Reis et al., 2019) ${ }^{[39,40]}$. Pan et al., (2002) ${ }^{[41]}$ showed that MAE was the best method for the extraction of tanshinones from Salvia miltiorrhiza. Dadi et al., (2019) ${ }^{[42]}$ extracted phenols and flavonoids from Moringa stenopetala leaves using conventional technique maceration and modern technique UAE and reported that UAE extracts gave significantly higher yield than macerated extracts.

\section{Quantitative Phytochemical Analysis Total phenol content}

The TPC of all 6 plant seeds is given in Fig. 2. The TPC varied with different seeds and with different extraction techniques. The trend of TPC in seeds was as follows: $A$. squamosa - MAE > DCE > MCE > UAE; $C$. papaya un-ripe $\mathrm{UAE}>\mathrm{DCE}>\mathrm{MAE}>\mathrm{MCE}$; $C$. papaya ripe - MAE > UAE $>\mathrm{MCE}>\mathrm{DCE}$; $C$. pentandra - UAE > MCE > MAE > DCE; T. ammi $-\mathrm{UAE}>\mathrm{MCE}=\mathrm{DCE}>\mathrm{MAE} ;$ T. foenum - graecum - $\mathrm{UAE}>\mathrm{MCE}>\mathrm{DCE}>\mathrm{MAE}$. Like extractive yield, maximum TPC was in modern extraction techniques UAE and MAE; in 4 plant seeds, UAE extracts had maximum TPC while in 2 plant seeds MAE extracts had maximum TPC. The extraction techniques definitely affected the TPC of all the plant seeds. Maximum TPC of all the plant seeds was in the range $23.3 \mathrm{mg} / \mathrm{g}$ to $51.6 \mathrm{mg} / \mathrm{g}$ (Fig. 2). Maximum TPC was in 9 min MAE extract of C. papaya ripe seed (Fig. 2D). Minimum TPC in all the plant seeds was in the range 11.5 $\mathrm{mg} / \mathrm{g}$ to $32.2 \mathrm{mg} / \mathrm{g}$. Minimum TPC was in the $9 \mathrm{~min}$ UAE extract of $A$. squamosa plant seed (Fig. 2A). In A. squamosa, maximum TPC was in 3 min microwaves exposed extracted $(23.3 \mathrm{mg} / \mathrm{g})$; ; in $C$. papaya un-ripe seed, it was in 9 min ultra sonicated extracted $(43.1 \mathrm{mg} / \mathrm{g})$; in $C$. papaya ripe seed, it 
was in $9 \mathrm{~min}$ microwave extracted $(51.6 \mathrm{mg} / \mathrm{g})$; in $C$. pentandra, it was in 6 min ultra sonicated extracted $(36.4$ $\mathrm{mg} / \mathrm{g}$ ); in $T$. ammi, it was in 9 min ultra sonicated extracted (41.9 mg/g)and in $T$. foenum - graecum, it was in 3 min ultra sonicated extracted $(30 \mathrm{mg} / \mathrm{g})$. When all the 6 plant seeds were compared, maximum TPC was in $C$. papaya ripe seed and minimum A. squamosa plant seed (Fig. 2D and 2A).

\section{Phenolic acid content (PAC)}

The PAC of all 6 seeds is given in Fig. 3. PAC varied with different plant seeds and with different extraction techniques. The trend of PAC in different plant seeds was as follows: $A$. squamosa - UAE > MAE = DCE > MCE; $C$. papaya un-ripe $\mathrm{DCE}>\mathrm{UAE}=\mathrm{MAE}>\mathrm{MCE} ; C$. papaya ripe $-\mathrm{MAE}>\mathrm{UAE}$ $>\mathrm{DCE}>\mathrm{MCE}$; $C$. pentandra $-\mathrm{MAE}>\mathrm{DCE}>\mathrm{UAE}=\mathrm{MCE}$; T. ammi - UAE > MCE > MAE > DCE; $T$. foenum - graecum - MAE > MCE > UAE = DCE. Like extractive yield and TPC, maximum PAC was in modern extraction techniques MAE and UAE. In 3 plant seeds MAE extracts had maximum PAC and in 2 plant seeds, UAE extracts had maximum PAC; while in remaining 1 plant seeds, DCE extracts had maximum PAC. The extraction techniques definitely affected the PAC of all the plant seeds. Maximum PAC of all the plant seeds was in the range $0.06 \mathrm{mg} / \mathrm{g}$ to $0.35 \mathrm{mg} / \mathrm{g}$ (Fig. 3). Maximum PAC was in 3 min UAE extract of T. ammi plant seed (Fig. 3E). Minimum PAC in all the plant seeds was in the range $0.01 \mathrm{mg} / \mathrm{g}$ to $0.18 \mathrm{mg} / \mathrm{g}$. Minimum PAC was in the MCE extract of $A$. squamosa plant seed (Fig. 3A) and 9 min MAE extract of $T$. foenum graecum plant seed (Fig. 3F). In $A$. squamosa, maximum PAC was in $3 \mathrm{~min}$ ultra sonicated extracted $(0.09 \mathrm{mg} / \mathrm{g})$; in in C. papaya un-ripe seed, it was in decoction extract $(0.08 \mathrm{mg} / \mathrm{g})$; in $C$. papaya ripe seed, it was in $9 \mathrm{~min}$ microwaves exposed extract $(0.13 \mathrm{mg} / \mathrm{g})$; in $C$. pentandra, it was in 6 min microwave exposed extract $(0.16$ $\mathrm{mg} / \mathrm{g}$ ); in $T$. ammi, it was in 3 min ultra sonicated extract $(0.35 \mathrm{mg} / \mathrm{g})$; in $T$. foenum - graecum, it was in $3 \mathrm{~min}$ microwaves exposed extract $(0.06 \mathrm{mg} / \mathrm{g})$. When all the 6 plant seeds were compared, maximum PAC was in T. ammi plant seed and minimum in $T$. foenum - graecum plant seed (Fig. $3 \mathrm{E}$ and $3 \mathrm{~F})$.

\section{Total flavonoids content (TFC)}

The TFC of all 6 plant seeds is given in Fig. 4. The TFC varied with plant seeds and with different extraction techniques. The trend of TFC in plant seeds was as follows: A. squamosa - UAE > MAE > DCE > MCE;C. papaya unripe $-\mathrm{UAE}>\mathrm{MAE}>\mathrm{DCE}>\mathrm{MCE}$; $C$. papaya ripe $-\mathrm{DCE}>$ $\mathrm{MCE}>\mathrm{UAE}>\mathrm{MAE} ; C$. pentandra $-\mathrm{UAE}>\mathrm{DCE}>\mathrm{MCE}>$ MAE; T. ammi - MAE > UAE > DCE > MCE; $T$. foenum graecum $-\mathrm{UAE}>\mathrm{MAE}>\mathrm{DCE}=\mathrm{MCE}$. Like extractive yield, TPC and PAC, maximum TFC was in modern extraction techniques UAE and MAE; in 4 plant seeds UAE extracts had maximum TFC and in remaining 2 plant seeds, in 1 plant seed, MAE extracts had maximum TFC and in 1 plant seed, DCE extract had maximum TFC. The extraction techniques definitely affected the TFC of all the plant seeds. Maximum TFC of all the plant seeds was in the range $8.5 \mathrm{mg} / \mathrm{g}$ to 14.87 $\mathrm{mg} / \mathrm{g}$ (Fig. 4). Maximum TFC was in DCE extract of $C$. papaya ripe seed (Fig. 4D). Minimum $\mathrm{TFC}$ in all the plant seeds was in the range $0 \mathrm{mg} / \mathrm{g}$ to $3.55 \mathrm{mg} / \mathrm{g}$. Minimum TFC was in the MAE extracts of $C$. papaya ripe seed and $C$. pentandra seed (Figs. 4DC and 4B). In fact, in these 2 plant seed MAE extracts, TFC was not detected. In A. squamosa, maximum TFC was in 9 min ultra sonicated extracted (11.95 $\mathrm{mg} / \mathrm{g}$ ); in $C$. papaya un-ripe seed, it was in 6 min ultra sonicated extract $(8.53 \mathrm{mg} / \mathrm{g})$; in $C$. papaya ripe seed, it was in decoction extract $(14.87 \mathrm{mg} / \mathrm{g})$; in $C$. pentandra, it was in 9 min ultra sonicated extract $(14.50 \mathrm{mg} / \mathrm{g})$; in $T$. ammi, it was in $9 \mathrm{~min}$ microwaves exposed extract $(9.20 \mathrm{mg} / \mathrm{g})$ and in $T$. foenum - graecum, it was in 6 min ultra sonicated extract $(9.43 \mathrm{mg} / \mathrm{g})$. When all the 6 plant seeds were compared, maximum TFC was in DCE extract of $C$. papaya ripe seed (Fig.4C) and minimum in MAE extracts of $C$. papaya ripe seed and C. pentandra seed (Fig. 4D and 4B).

\section{Flavonol content (FC)}

The flavonol content of all 6 plant seeds is given in Fig. 5. The FC varied with different plant seeds and with different extraction techniques. The trend of FC in different plant seeds was as follows: A. squamosa - UAE > MAE > DCE > MCE; C. papaya un-ripe - MAE > UAE > DCE > MCE; C. papaya ripe - $\mathrm{DCE}>\mathrm{MCE}>\mathrm{UAE}>\mathrm{MAE} ; C$. pentandra - MCE > $\mathrm{UAE}>\mathrm{DCE}>\mathrm{MAE}$; T. ammi - MAE > UAE > DCE > MCE; T. foenum - graecum - MAE > UAE > MCE > DCE. Like extractive yield, TPC, PAC, TFC maximum FC was in modern extraction techniques MAE and UAE; in 3 plant seeds MAE extracts had maximum FC and in 1 plant seeds, UAE extracts had maximum FC; while in remaining 2 plant seeds, one in DCE extract and other one in MCE extracts. The extraction techniques definitely affected the FC of all the plant seeds. Maximum FC of all the plant seeds was in the range $12.5 \mathrm{mg} / \mathrm{g}$ to $43.18 \mathrm{mg} / \mathrm{g}$ (Fig. 5). Maximum FC was in DCE extract of $C$. papaya ripe plant seed (Fig. 5D). Minimum $\mathrm{FC}$ in all the plant seeds was in the range $0 \mathrm{mg} / \mathrm{g}$ to 15.36 $\mathrm{mg} / \mathrm{g}$. Minimum FC was in MAE and UAE extracts of $C$. papaya ripe seed (Fig. 5D) and MAE extracts of $C$. pentandra extract (Fig. 5B). In A. squamosa, maximum FC was in 9 min ultra sonicated extracted $(34.27 \mathrm{mg} / \mathrm{g})$; in $C$. papaya un-ripe seed, it was in 9 min microwaves exposed extract $(24.45$ $\mathrm{mg} / \mathrm{g})$; in C. papaya ripe seed, it was in DCE extract $(43.18$ $\mathrm{mg} / \mathrm{g})$; in $C$. pentandra, it was in MCE extract $(12.50 \mathrm{mg} / \mathrm{g})$; in T. ammi, it was in 9 min microwaves extract $(27.18 \mathrm{mg} / \mathrm{g})$ and in $T$. foenum - graecum, it was in $3 \mathrm{~min}$ microwaves exposed extract $(27.77 \mathrm{mg} / \mathrm{g})$. When all the 6 plant seeds were compared, maximum FC was in C. papaya ripe seed (Fig. 5D) and minimum $\mathrm{FC}$ was in MAE and UAE extracts of $C$. papaya ripe seed (Fig. 5D), and MAE extracts of $C$. pentandra extract (Fig. 5B).

\section{Proanthocynidin content (PC)}

The PC of all 6 plant seeds is given in Fig. 6. The PC varied with plant seeds and with different extraction techniques. The trend of PC in plant seeds was as follows: A. squamosa - DCE $>\mathrm{UAE}>\mathrm{MAE}>\mathrm{MCE}$; $C$. papaya un-ripe - MAE > UAE > $\mathrm{DCE}>\mathrm{MCE}$; $C$. papaya ripe - UAE > MAE > MCE > DCE; C. pentandra - UAE > MAE > MCE > DCE; T. ammi - UAE $>$ DCE > MAE > MCE; $T$. foenum - graecum $-\mathrm{UAE}>\mathrm{DCE}$ $>$ MAE > MCE. Like extractive yield, TPC, PAC, TFC, FC, maximum $\mathrm{PC}$ was in modern extraction techniques UAE and MAE; in 4 plant seeds, UAE extracts had maximum PC and in 1plant seeds, MAE extracts had maximum PC while in remaining 1 plant seeds, DCE extract showed maximum PC. The extraction techniques definitely affected the $\mathrm{PC}$ of all the plant seeds. Maximum PC of all the plant seeds was in the range $0.9 \mathrm{mg} / \mathrm{g}$ to $1.7 \mathrm{mg} / \mathrm{g}$ Fig. 6. Maximum PC was in $6 \mathrm{~min}$ UAE extract of T. ammi plant seed (Fig. 6E). Minimum PC in all the plant seeds was in the range $0 \mathrm{mg} / \mathrm{g}$ to $0.7 \mathrm{mg} / \mathrm{g}$. Minimum PC was in the MCE extract of $A$. squamosa plant seed (Fig. 6A) . In A. squamosa, maximum PC was in DCE extract $(1.64 \mathrm{mg} / \mathrm{g})$; in C. papaya un-ripe seed, it was in $6 \mathrm{~min}$ 
microwaves exposed extract $(1.41 \mathrm{mg} / \mathrm{g})$; in $C$. papaya ripe seed, it was in 9 min ultra sonicated extract $(1.30 \mathrm{mg} / \mathrm{g})$; in $C$. pentandra, it was in $3 \mathrm{~min}$ ultra sonicated extract $(0.99 \mathrm{mg} / \mathrm{g})$; in T. ammi, it was in $6 \mathrm{~min}$ ultra sonicated extract $(1.75 \mathrm{mg} / \mathrm{g})$ and in $T$. foenum - graecum, it was in 9 min ultra sonicated extract $(2.43 \mathrm{mg} / \mathrm{g})$. When all the 6 plant seeds were compared, maximum PC was in 6 min UAE extract of $T$. ammi plant seed and minimum in A. squamosa plant seed (Figs. 6E and 6A).

Extraction methods greatly influence extraction yield of phenolic compounds and their antioxidant properties and has been studied widely (Das et al., 2019) ${ }^{[43]}$. Several researchers proved that modern methods UAE and MAE gave better yield and bioactive compounds from different plant materials. They also showed better antioxidant activity; though they are some reports where traditional methods were also good or no difference between traditional or modern methods. Rasheed $e t$ al. (2018) [44] evaluated different extraction methods (decoction, infusion, and maceration) and their effect on the bioactive compound profile of Hibiscus sabdariffa extracts; cold maceration was good for extracting anthocyanins and infusion method was good for recovering organic acids from Hibiscus sabdariffa. No difference in antioxidant activities of Propolis by conventional or modern methods (de Oliveira Reis et al., 2019) ${ }^{[40]}$.

Anaya-Esparza et al., (2018) ${ }^{[45]}$ obtained higher phenolic content by UAE than by stirring or thermal decoction from Justicia spicigera leaves. Yield, phenols, flavonoids and DPPH scavenging activity was more with non conventional method UAE than with conventional method MCE from peels of different citrus cultivars (Saini et al., 2019) ${ }^{[46]}$. AguilarHernández et al., (2019) [47] used UAE for extracting polyphenols from seed, peel, and columella and pulp from Annona muricata. UAE increases extraction efficiency of various phytoconstituents from different plant materials for eg. phenolic compounds, antioxidants, and anthocyanins from Vitis vinifera seeds (Ghafoor et al., 2009) ${ }^{[48]}$, carnosic acid and rosmarinic acid from Rosmarinus officinalis (Ge et al., 2012) ${ }^{[49]}$, procyanidins from the Perilla frutescens seed hull (Li et al., 2019) ${ }^{[50]}$, anthocyanins from cranberries (Klavins et al., 2018), flavonoids from Andrographis echioides (Ramasamy et al., 2019) ${ }^{[52]}$.

MAE has also been successfully employed for extraction of resveratrol from Polygonum cuspidatum (Chen, 2013) [53], alkaloids from lotus plumule (Xiong et al., 2016) [54], hemicelluloses from lignocellulosic materials (Mihiretu et al., 2017) ${ }^{[55]}$, phenol, flavonoid and anthocyanins from Hibiscus sabdariffa calyx (Nguyen, 2020), phenols and flavonoids from Phyllostachys pubescens shoots (Milani et al., 2020) ${ }^{[57]}$. Li et al., 2017) ${ }^{[58]}$ compared traditional methods (Soxhlet extraction and maceration extraction) and modern method MAE for extracting phenols and evaluating antioxidant activity of Gordonia axillaris fruit and once again confirmed that modern method MAE gave better results.

Thus in accordance with reported literature, in the present work also, the modern methods MAE and UAE were better for extractive yield and extracting bioactive molecules like phenols, flavonoids, flavonols, phenolic acids and proanthocynidins. MAE and UAE are green extraction methods as compared to traditional techniques and provide shorter extraction time, enhanced extraction efficiency, increased reproducibility, less solvent and energy consumption, simple and prevention of thermo degradation of bioactive compounds (Da Porto \& Natolino, 2018; Savie and Gajic, 2020) ${ }^{[59,60]}$. However, for every plant optimization of various parameters involved in the techniques (MAE and UAE) is needed and necessary (Aydar et al., 2017, Li et al., 2017, Ramasamy et al., 2020) ${ }^{[58,61]}$.

\section{Antioxidant activity}

The antioxidant activity was evaluated by four different in vitro antioxidant assays. All the extracts, irrespective of the extraction methods showed very poor antioxidant activity. None of the extracts showed DPPH free radical scavenging activity. In almost all the extracts, IC50 values were more than $1000 \mathrm{ug} / \mathrm{ml}$. SO activity also showed almost similar trend like that of DPPH. In $C$. papaya ripe and $C$. pentandra, very poor SO activity was found; their $\mathrm{IC}_{50}$ values were more than $1000 \mu \mathrm{g} / \mathrm{ml}$. In A. squamosa, T. ammi and T. foenum graecum few extracts showed little SO activity while most of the extracts displayed $\mathrm{IC}_{50}$ value more than $1000 \mu \mathrm{g} / \mathrm{ml}$.

All the 6 plant seed extracts showed ABTS cation radical scavenging except $A$. squamosa extracts, but to a varied level. In 2 plants, lowest $\mathrm{IC}_{50}$ value was in modern techniques while in 3 plants, it was in traditional techniques (Table 1) clearly indicated that there is no universal criteria and it varies from plant to plant. In $C$. papaya unripe seed extracts, the $\mathrm{IC}_{50}$ values ranged from $100.5-348 \mu \mathrm{g} / \mathrm{ml}$ and lowest was in maceration extract $(100.5 \mu \mathrm{g} / \mathrm{ml})$; in $C$. papaya ripe seed extracts, the $\mathrm{IC}_{50}$ values ranged from $256-402 \mu \mathrm{g} / \mathrm{ml}$ and lowest was in 9 min microwaves exposed extract $(256 \mu \mathrm{g} / \mathrm{ml})$; in $C$. pentandra seed extracts, the $\mathrm{IC}_{50}$ values ranged from $368-656 \mu \mathrm{g} / \mathrm{ml}$ and lowest was in $6 \mathrm{~min}$ ultra sonicated extract $(368 \mu \mathrm{g} / \mathrm{ml})$; in $T$. ammi seeds extracts, the $\mathrm{IC}_{50}$ values ranged from $70-190 \mu \mathrm{g} / \mathrm{ml}$ and lowest was in 9 min ultra sonicated extract $(70 \mu \mathrm{g} / \mathrm{ml})$; in $T$. foenum - graecum seed extracts, the $\mathrm{IC}_{50}$ values ranged from $201-450 \mu \mathrm{g} / \mathrm{ml}$ and lowest was in decoction extract $(201 \mu \mathrm{g} / \mathrm{ml})$.

The extraction techniques definitely affected the FRAP content of all the plants and there was no general trend; it varied from plant to plant. In A. squamosa maximum FRAP content was in $3 \mathrm{~min}$ microwaves exposed extract $(0.65 \mathrm{M} / \mathrm{g})$ while in $C$. papaya unripe seed it was in 9 min microwaves exposed extract $(2.81 \mathrm{M} / \mathrm{g})$; in $C$. papaya ripe seed, it was in 3 min ultra sonicated extract $(3.58 \mathrm{M} / \mathrm{g})$; in $C$. pentandra, it was in decoction extract $(2.04 \mathrm{M} / \mathrm{g})$; in $T$. ammi, it was in maceration extract $(2.25 \mathrm{M} / \mathrm{g})$; in T. foenum - graecum, it was in $3 \mathrm{~min}$ ultra sonicated extract $(1.18 \mathrm{M} / \mathrm{g})$. All the extracts showed FRAP content but amongst all the plants, maximum content was in $C$. papaya ripe seed extract and minimum was in A. squamosa seed extract. Overall content was in the order: C. papaya ripe seed $>C$. papaya ripe seed $>T$. ammi $>C$. pentandra $>$ T. foenum - graecum $>$ A. squamosa.

In the present study, weak antioxidant activity was found in all seed extracts extracted by different extraction techniques, which could be the result of the poor solubility of polyphenols and other bioactive molecules in the water extract (Bravo et al., 2007) ${ }^{[62]}$. Similar results i.e. poor antioxidant activities by water extracts in A. saligna flowers is reported by Al-Huqail et al., (2019) [63]. Tohma et al., (2016) ${ }^{[64]}$ reported less antioxidant activity in water extract as compared to ethanol extract in Salvia species. However, in some plants water can be used as effective extraction solvent as demonstrated by $\mathrm{Vu}$ et al., (2019) ${ }^{[65]}$; they used water in MAE for extracting phenols and antioxidants from banana peels. It can be concluded that extraction method, extraction conditions and extraction solvents directly influence extractive yield and extractability of bioactive compounds or phytoconstituents and antioxidant activities in medicinal plants. 

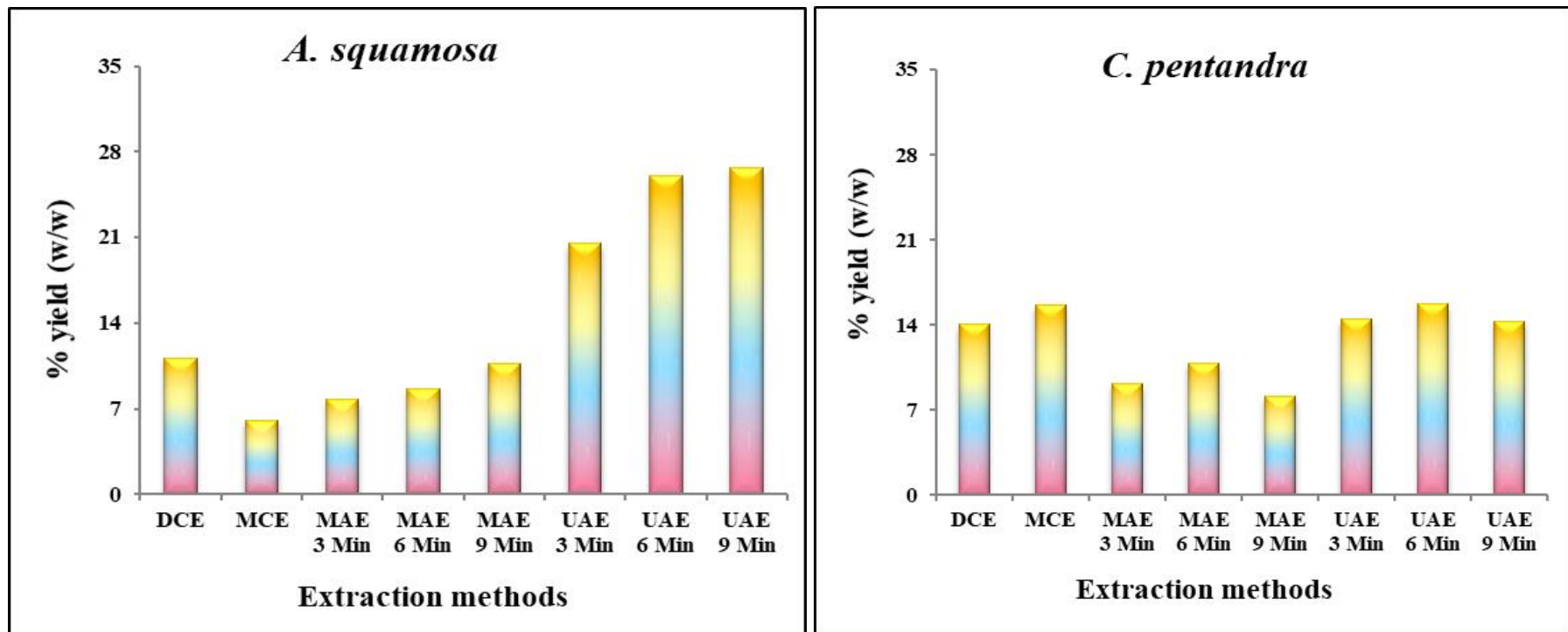

A.

B.
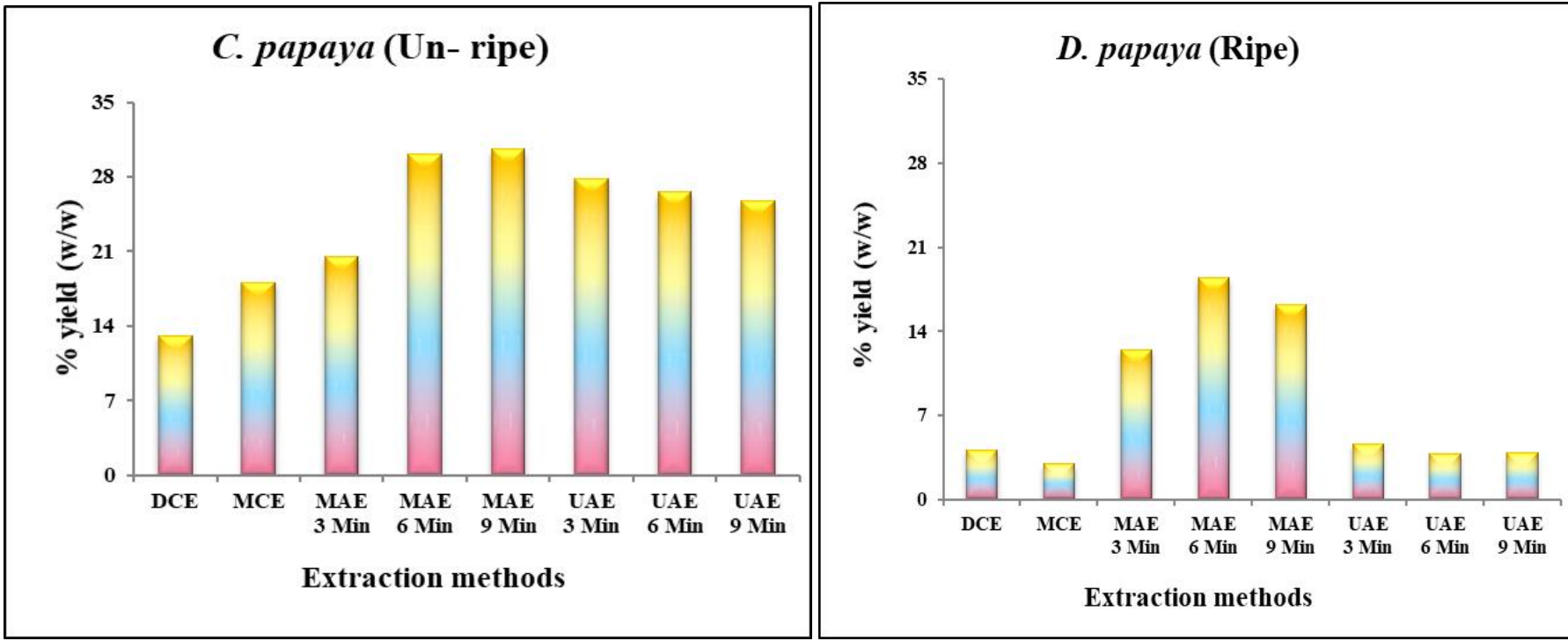

C.

D.
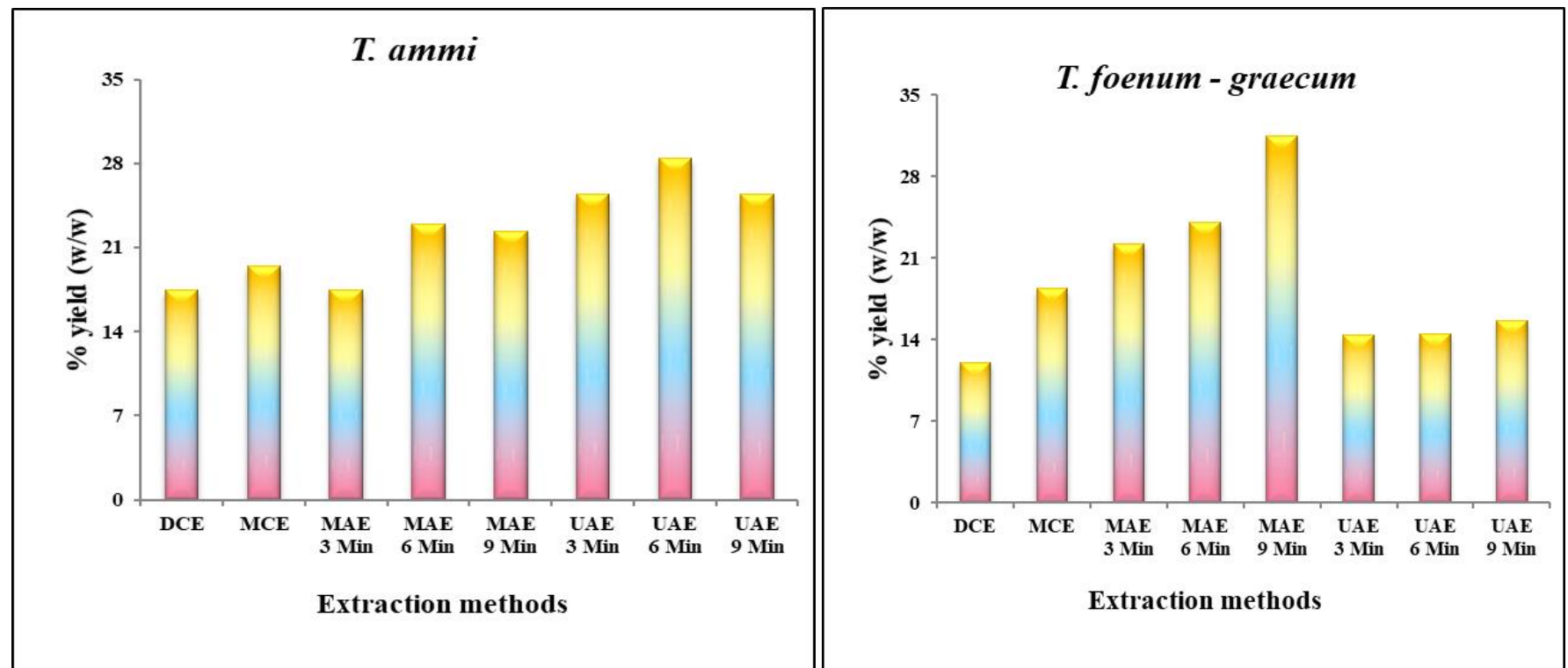

E.

F.

Fig 1: Effect of extraction methods and time on extractive yield of some medicinal plant seeds 


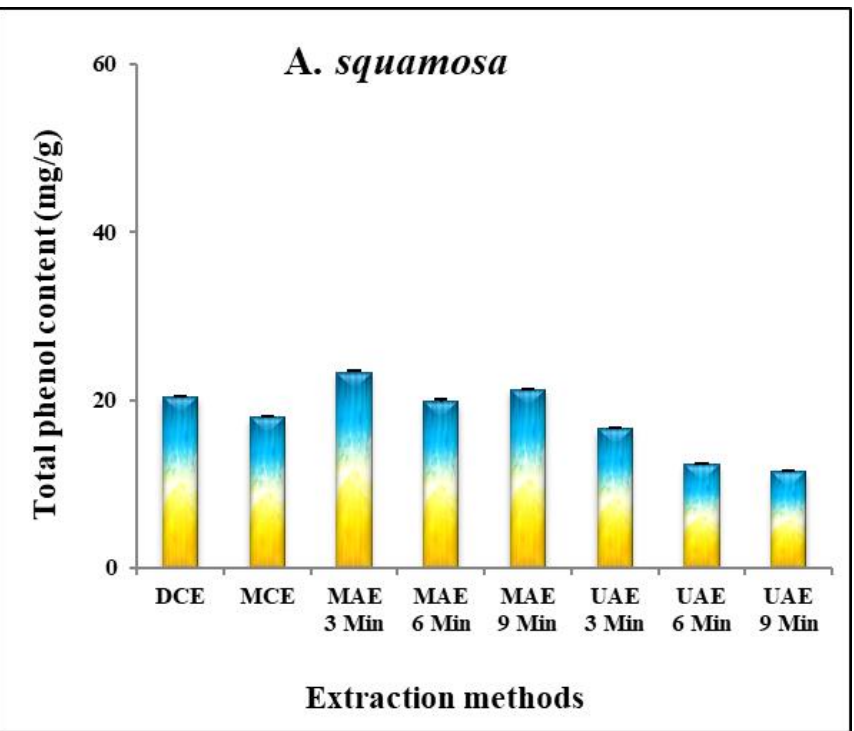

A.

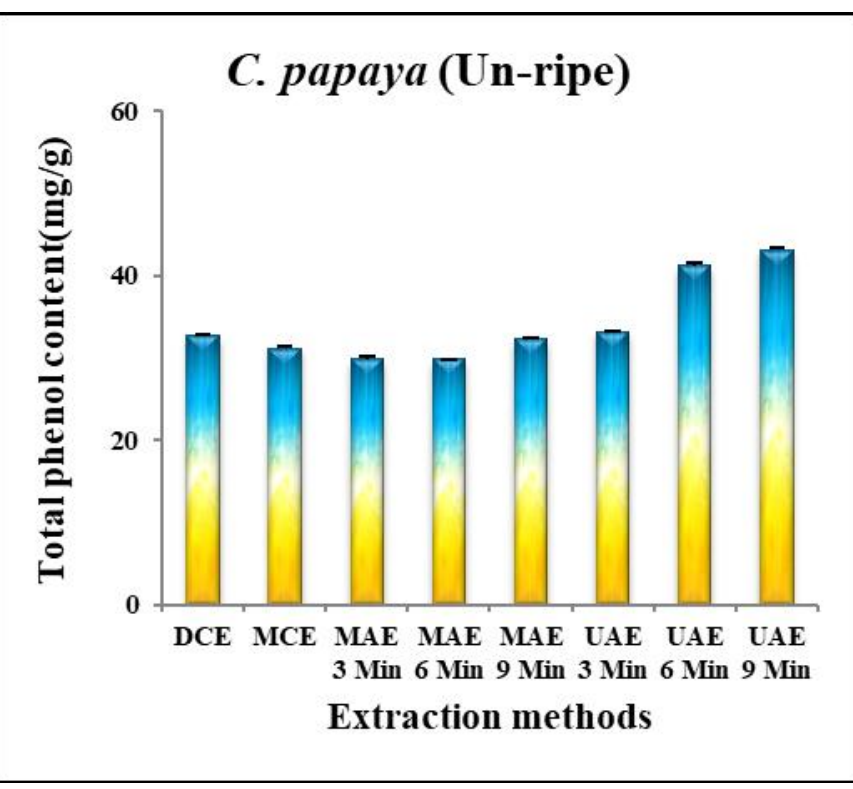

C.

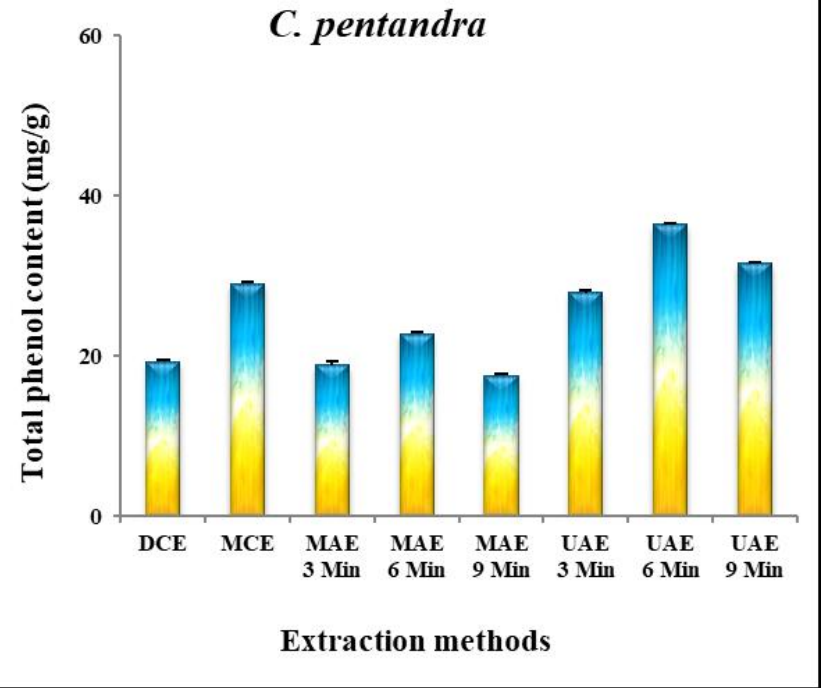

B.

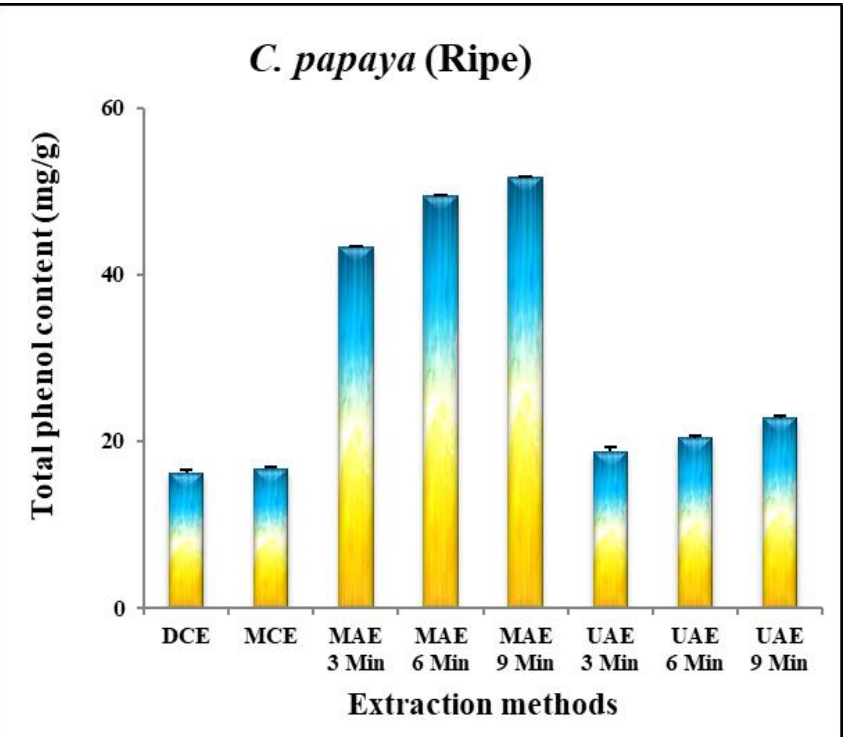

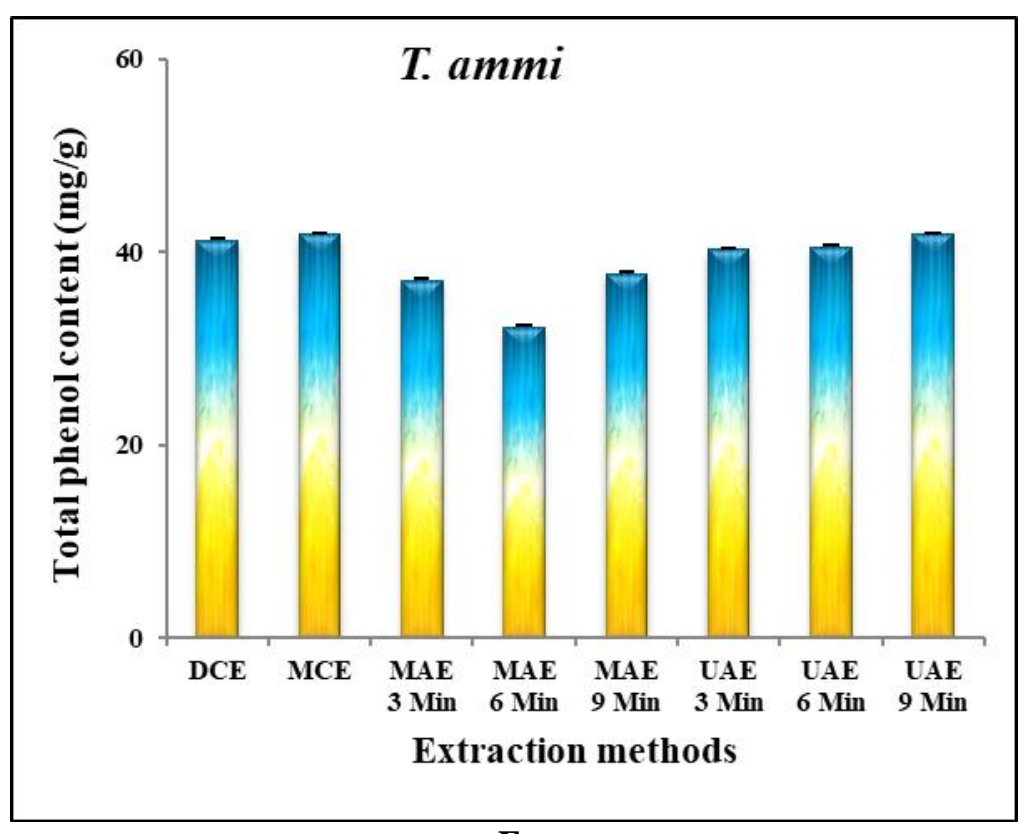

D.

E.

Fig 2: Effect of extraction methods and time on total phenol content ofsome medicinal plant seeds 


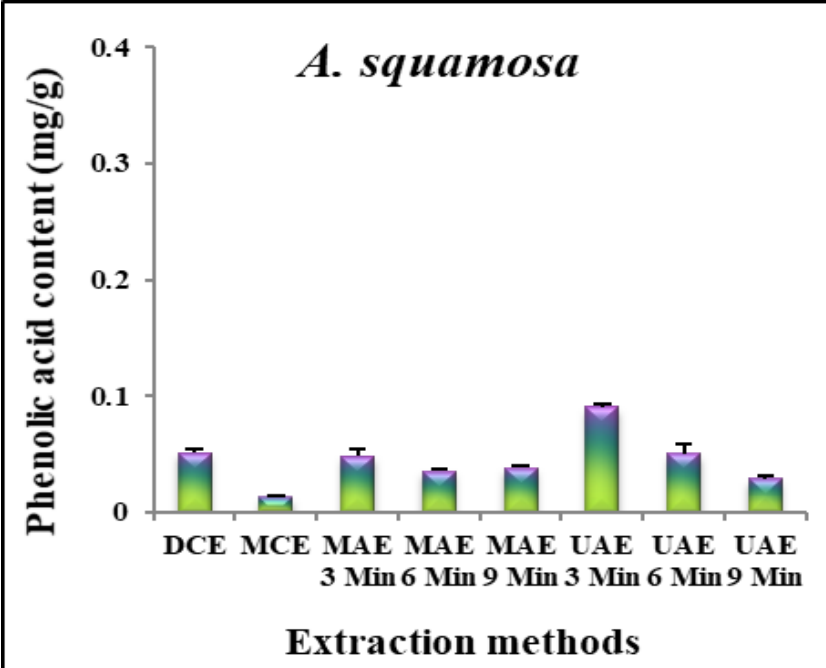

A.

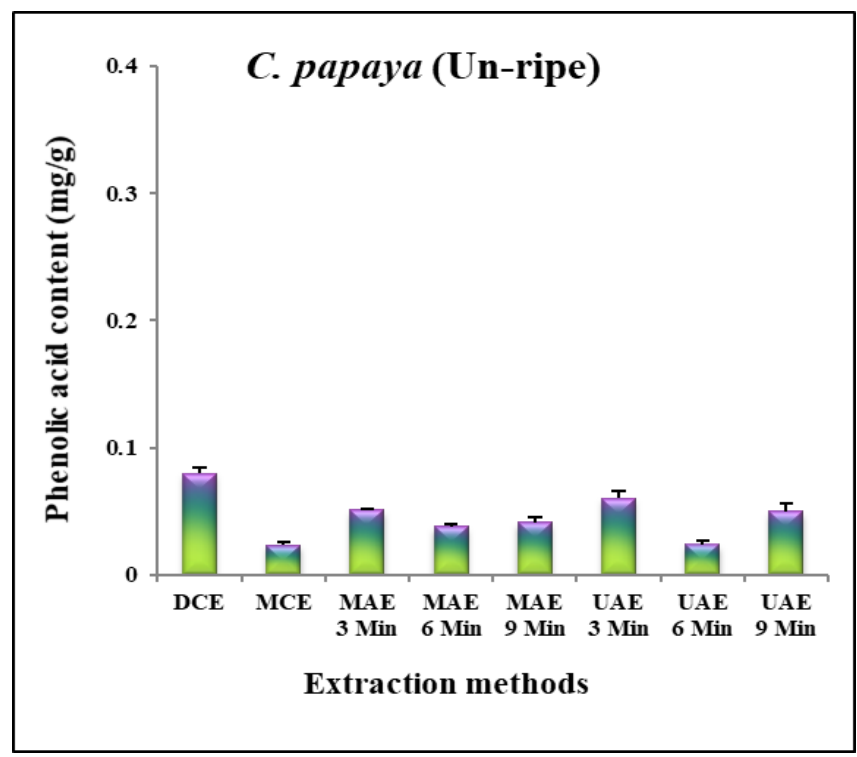

C.

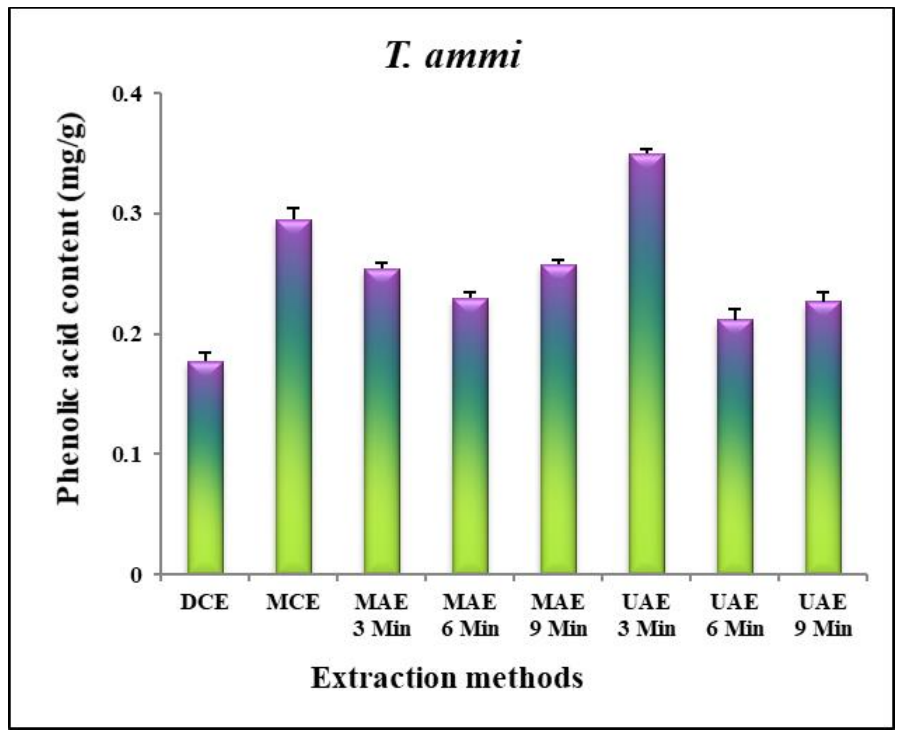

E.

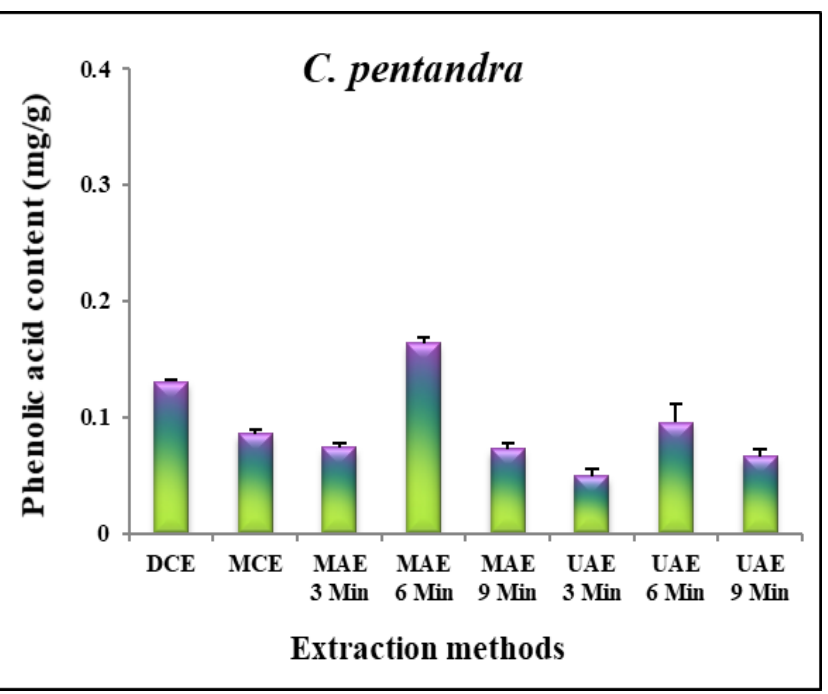

B.

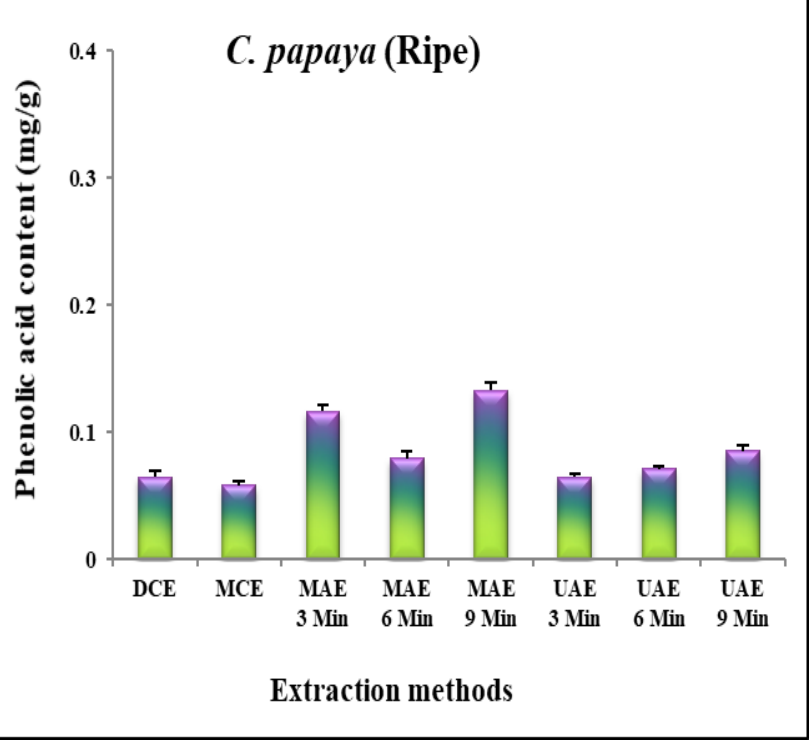

D.

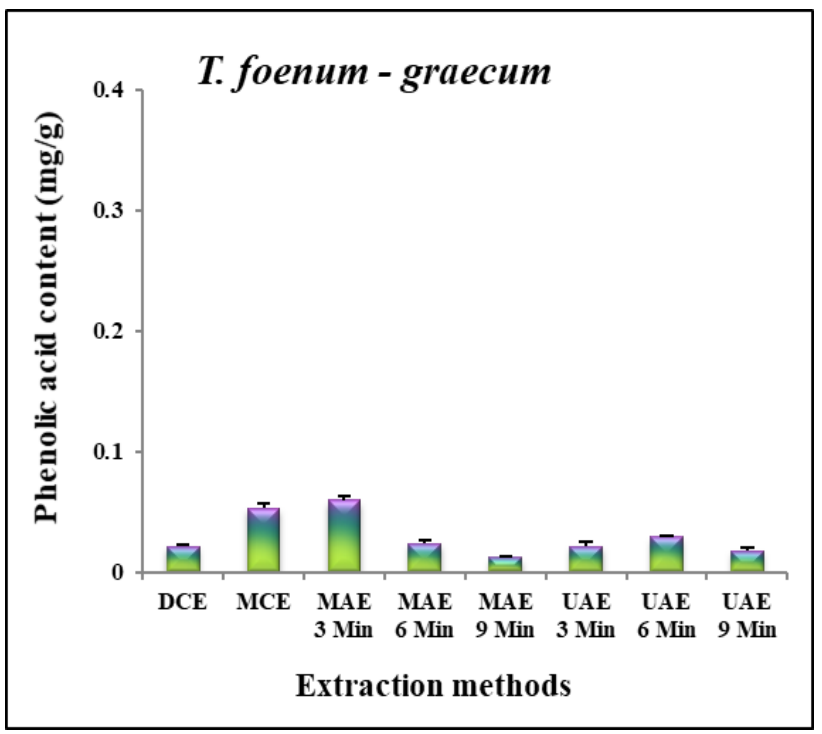

F.

Fig 3: Effect of extraction methods and time on phenolic acid content of some medicinal plant seeds 


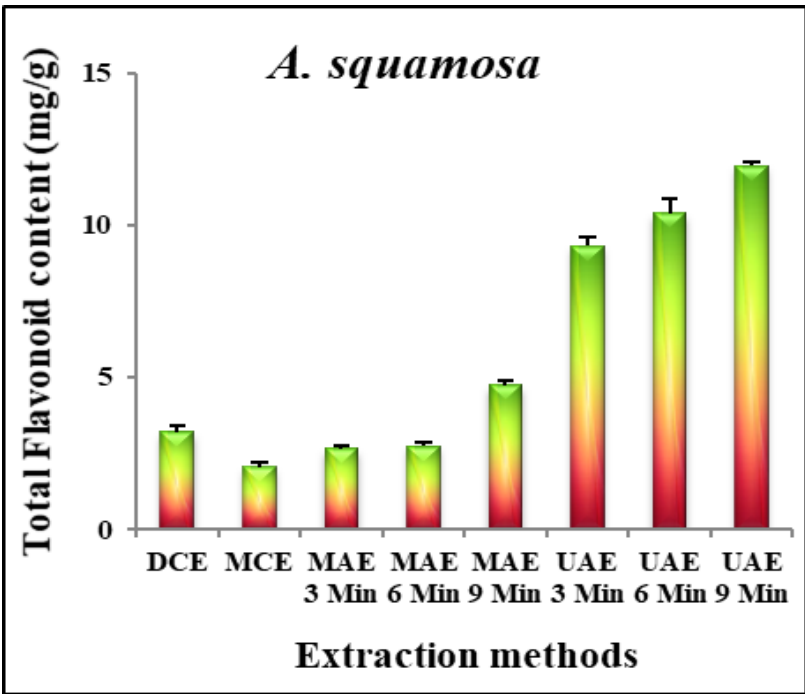

A.

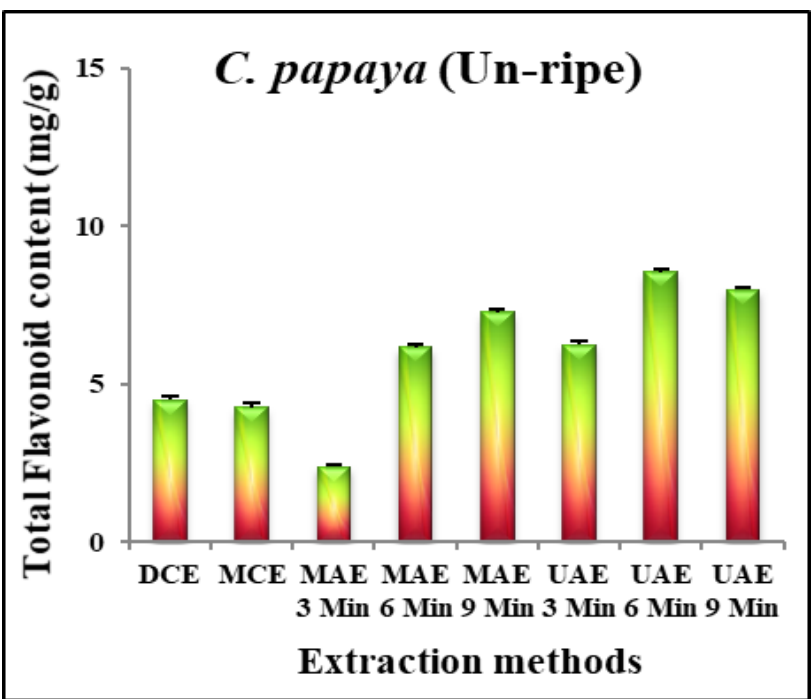

C.

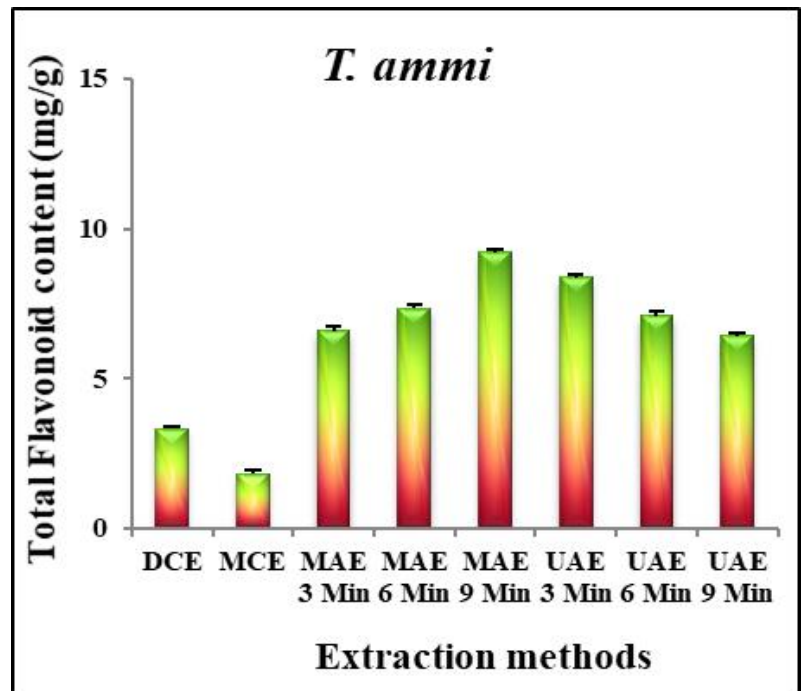

E.

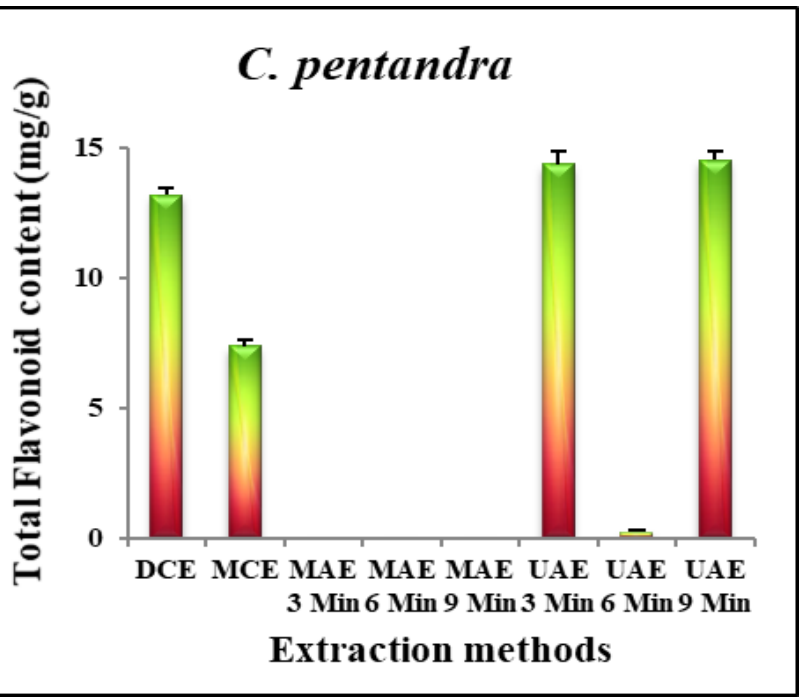

B.

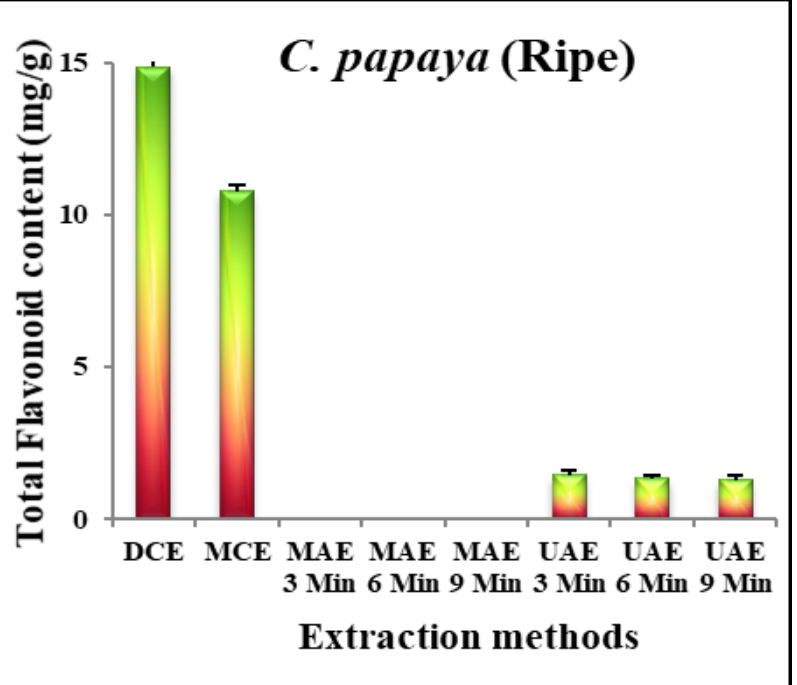

D.

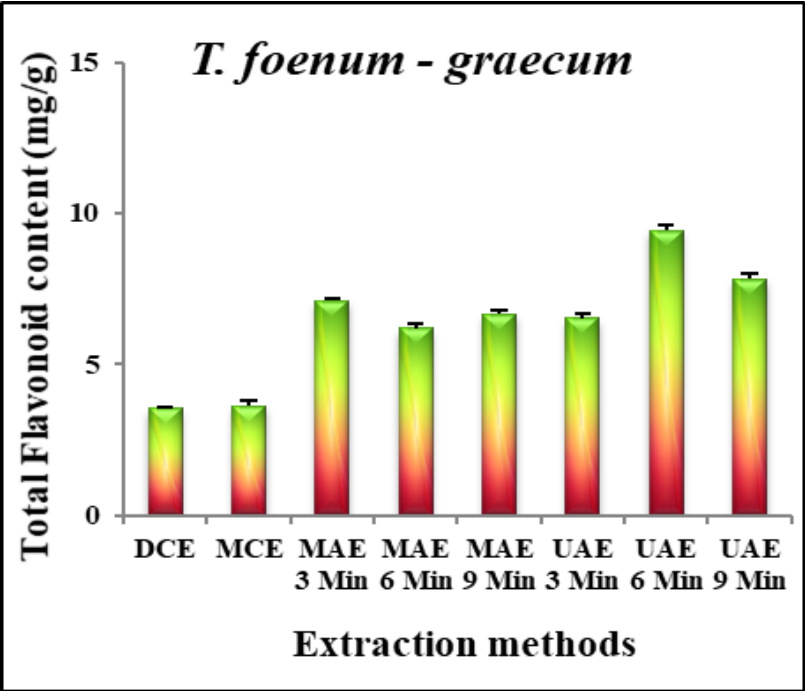

F.

Fig 4: Effect of extraction methods and time on total flavonoid content of some medicinal plant seeds 


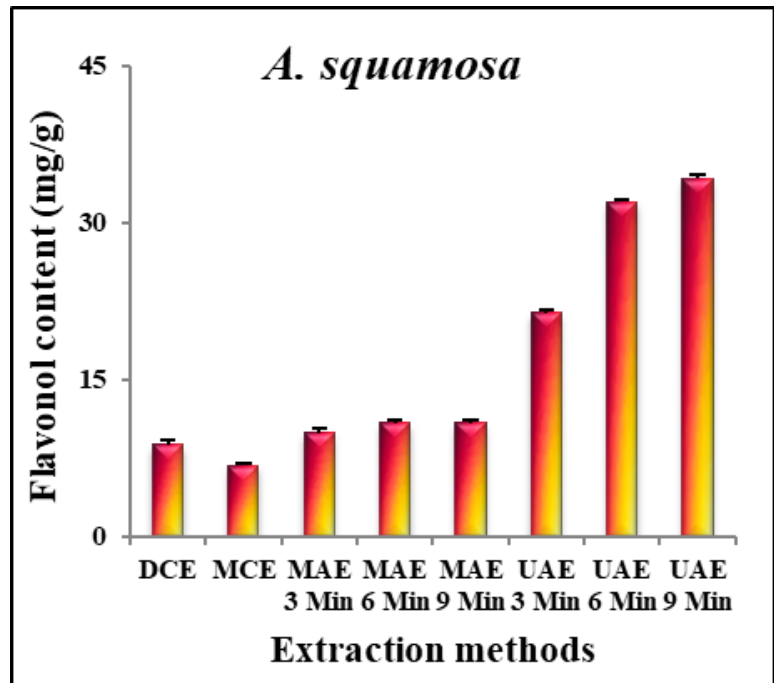

A.

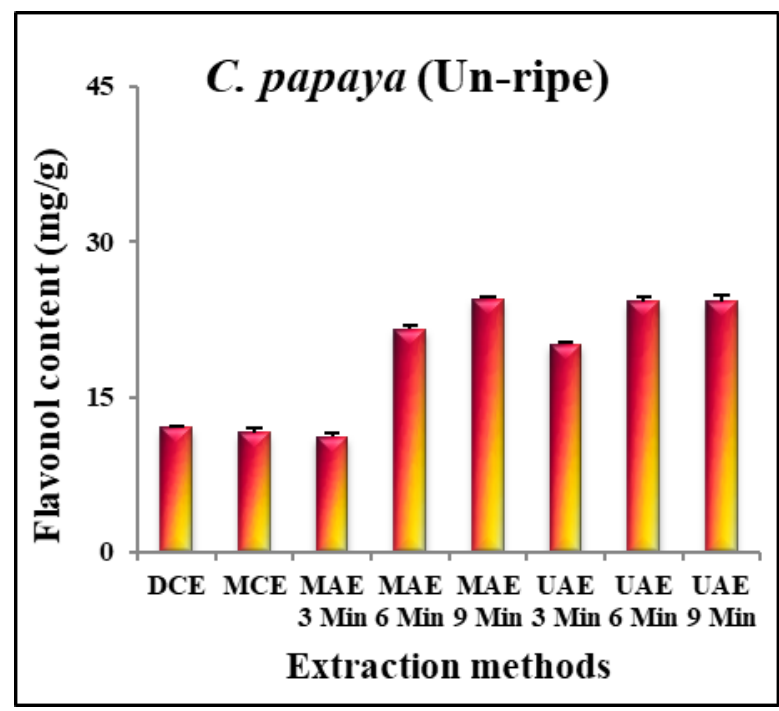

C.

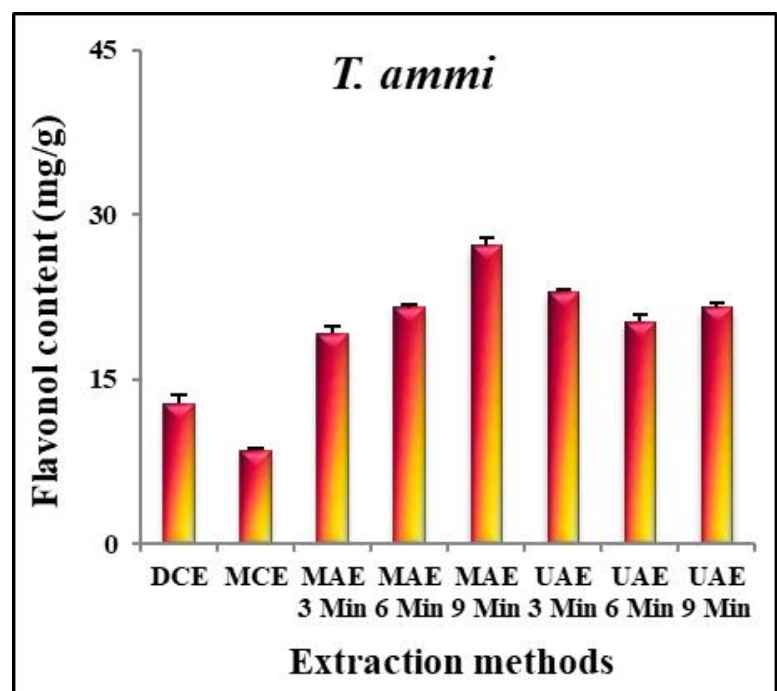

E.

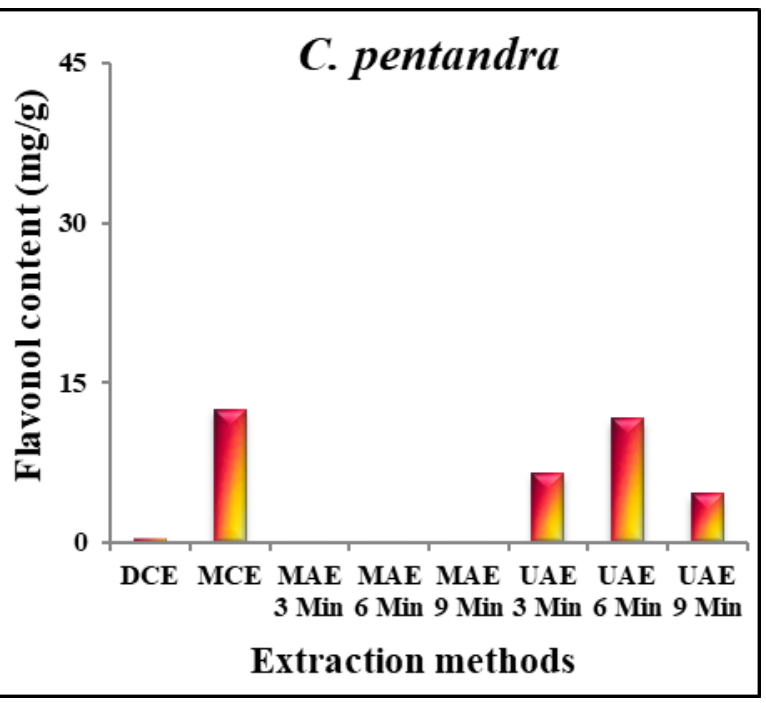

B.

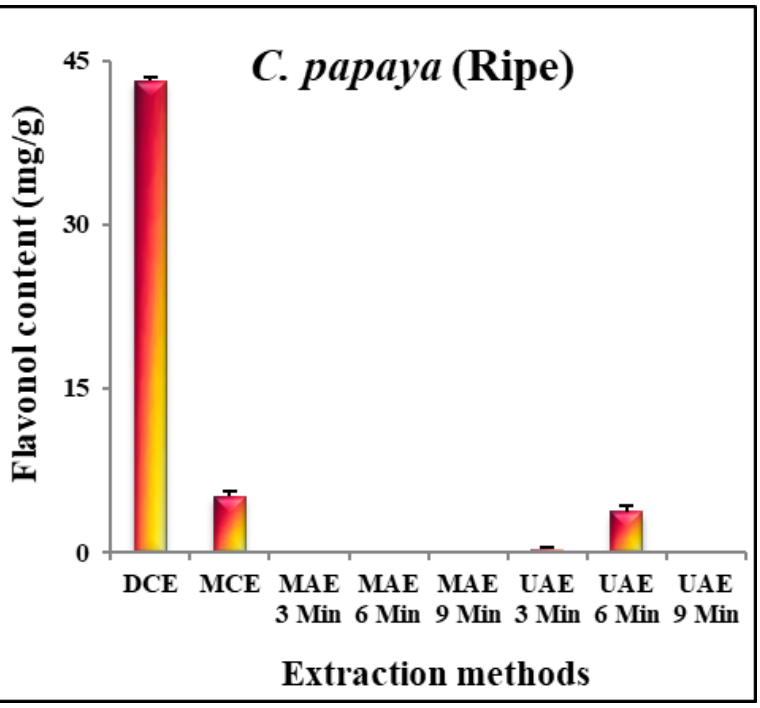

D.

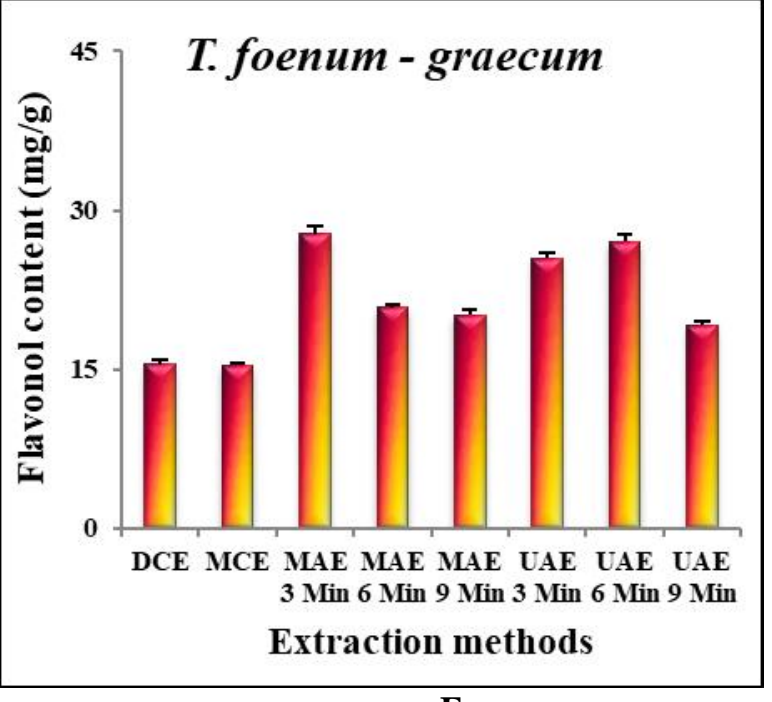

F.

Fig 5: Effect of extraction methods and time on flavonol content of some medicinal plant seeds 


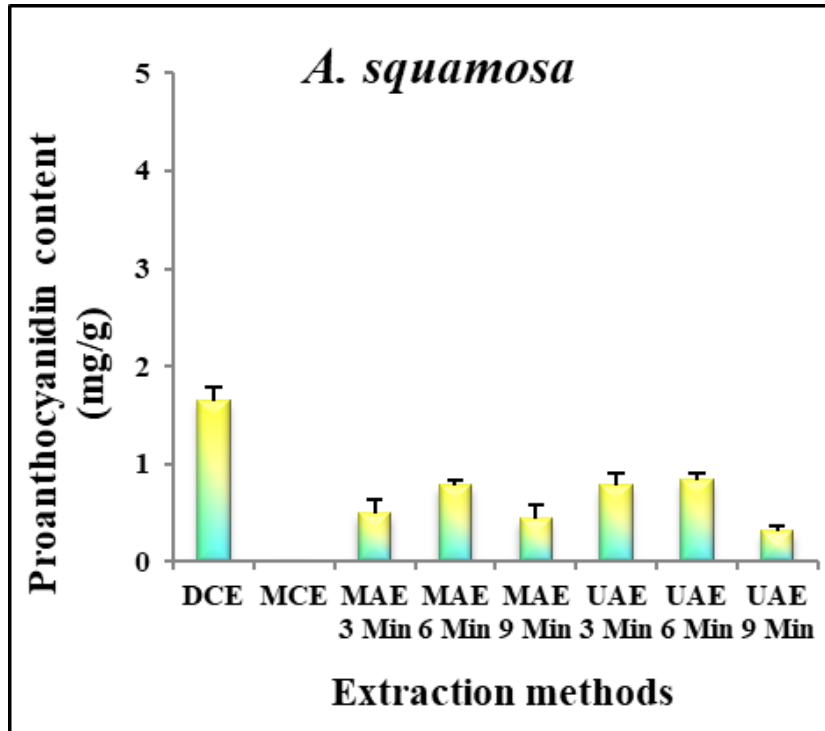

A.

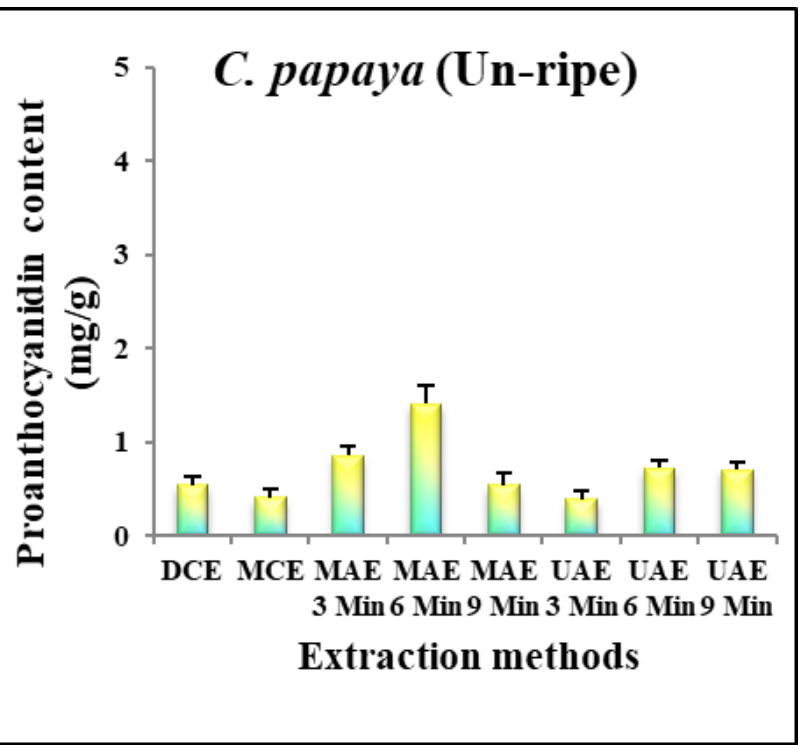

C.

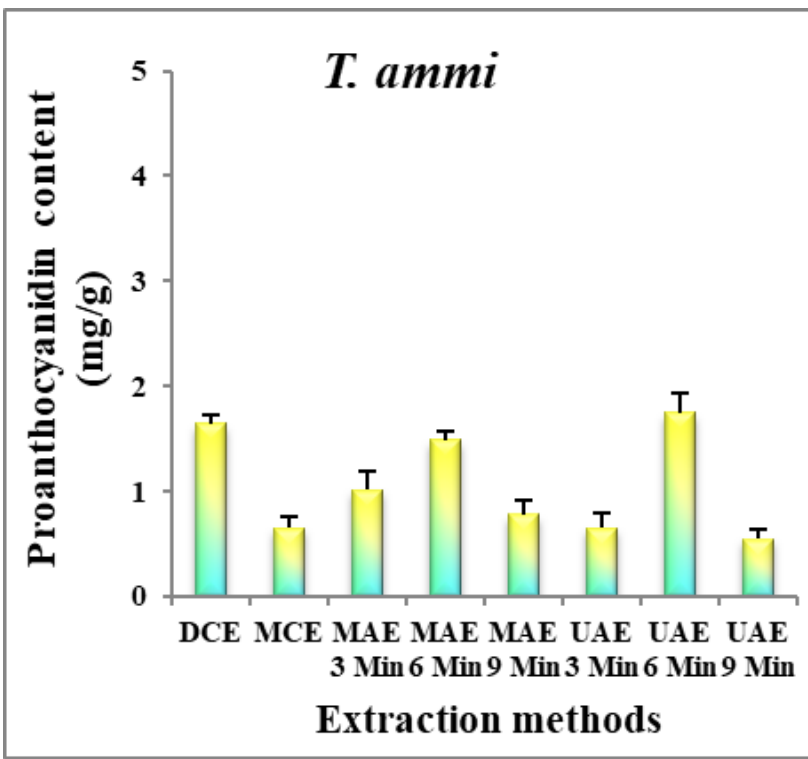

E.

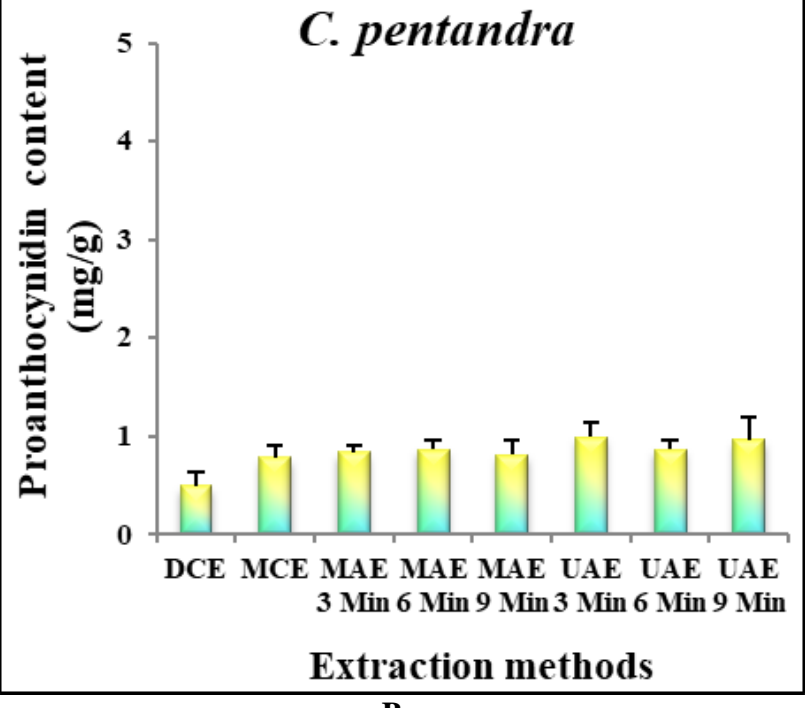

B.

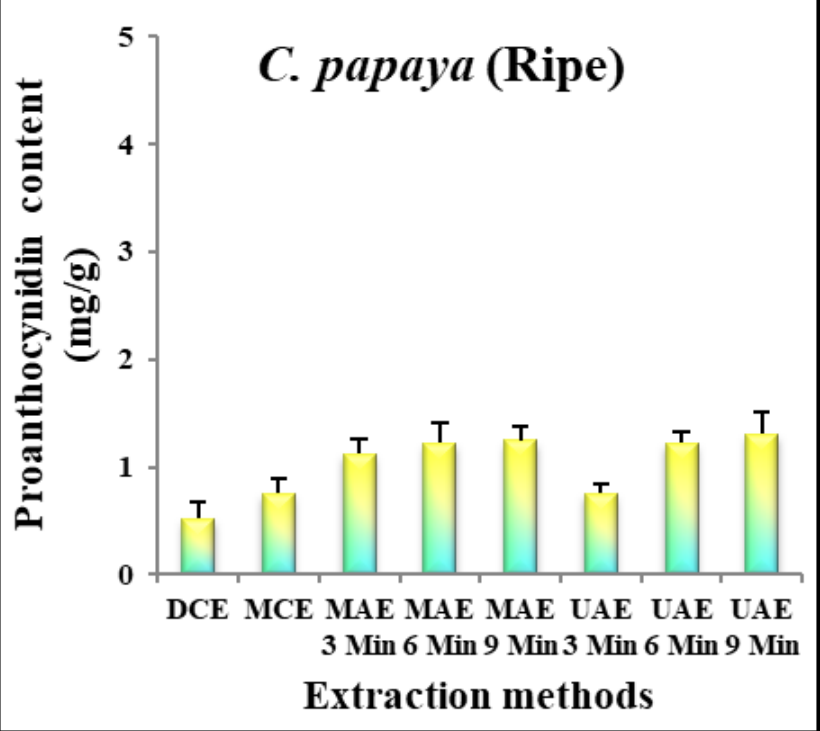

D.

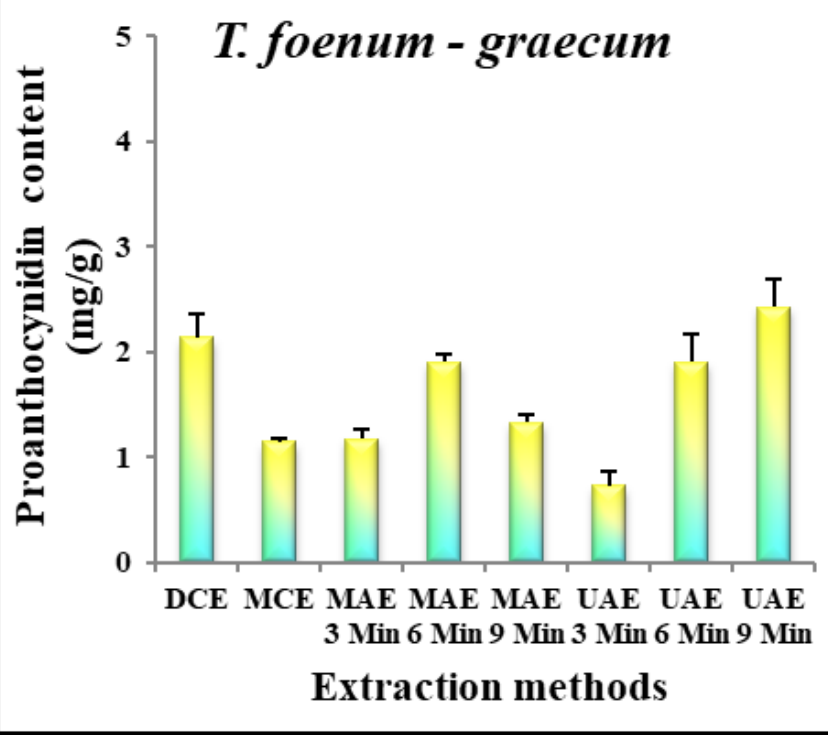

F.

Fig 6: Effect of extraction methods and time on Proanthocyanidin content of some medicinal plant seeds 
Table 1: $\mathrm{IC}_{50}$ values of DPPH, SO, ABTS and FRAP of different plants seed extracts

\begin{tabular}{|c|c|c|c|c|c|c|}
\hline \multirow{2}{*}{ Plants Name } & \multirow{2}{*}{\multicolumn{2}{|c|}{ Seed extracts }} & \multicolumn{3}{|c|}{ IC $_{50}$ Values $(\mu \mathrm{g} / \mathrm{ml})$} & \multirow{2}{*}{$\begin{array}{l}\text { FRAP } \\
(\mathrm{M} / \mathrm{g})\end{array}$} \\
\hline & & & DPPH & SO & ABTS & \\
\hline \multirow{8}{*}{ A. squamosa } & \multicolumn{2}{|c|}{ DCE } & $>1000$ & $>1000$ & $>1000$ & 0.613 \\
\hline & \multicolumn{2}{|c|}{$\mathrm{MCE}$} & $>1000$ & 360 & $>1000$ & 0.408 \\
\hline & \multirow{3}{*}{ MAE } & $3 \mathrm{~min}$ & $>1000$ & $>1000$ & 720 & 0.659 \\
\hline & & $6 \mathrm{~min}$ & $>1000$ & $>1000$ & $>1000$ & 0.629 \\
\hline & & $9 \mathrm{~min}$ & $>1000$ & 384 & 480 & 0.645 \\
\hline & \multirow{3}{*}{ UAE } & $3 \mathrm{~min}$ & $>1000$ & $>1000$ & $>1000$ & 0.573 \\
\hline & & $6 \mathrm{~min}$ & $>1000$ & $>1000$ & $>1000$ & 0.507 \\
\hline & & $9 \min$ & $>1000$ & $>1000$ & $>1000$ & 0.603 \\
\hline \multirow{8}{*}{ C. papaya (Un-ripe) } & \multicolumn{2}{|c|}{ DCE } & $>1000$ & 544 & 228 & 1.968 \\
\hline & \multicolumn{2}{|c|}{ MCE } & 456 & 512 & 100.5 & 2.645 \\
\hline & \multirow{3}{*}{ MAE } & $3 \mathrm{~min}$ & $>1000$ & 504 & 243 & 1.549 \\
\hline & & $6 \mathrm{~min}$ & $>1000$ & $>1000$ & 348 & 1.464 \\
\hline & & $9 \min$ & $>1000$ & $>1000$ & 336 & 2.811 \\
\hline & \multirow{3}{*}{ UAE } & $3 \mathrm{~min}$ & $>1000$ & $>1000$ & 207.5 & 1.939 \\
\hline & & $6 \mathrm{~min}$ & $>1000$ & $>1000$ & 195 & 1.643 \\
\hline & & $9 \mathrm{~min}$ & 195 & $>1000$ & 182.5 & 2.467 \\
\hline \multirow{8}{*}{ C. papaya (Ripe) } & \multicolumn{2}{|c|}{$\mathrm{DCE}$} & $>1000$ & $>1000$ & 402 & 2.328 \\
\hline & \multicolumn{2}{|c|}{ MCE } & $>1000$ & $>1000$ & 340 & 2.016 \\
\hline & & $3 \mathrm{~min}$ & $>1000$ & $>1000$ & 288 & 2.104 \\
\hline & \multirow[t]{2}{*}{ MAE } & $6 \mathrm{~min}$ & 824 & $>1000$ & 324 & 2.291 \\
\hline & & $9 \min$ & $>1000$ & $>1000$ & 256 & 2.520 \\
\hline & \multirow{3}{*}{ UAE } & $3 \mathrm{~min}$ & $>1000$ & $>1000$ & 390 & 3.584 \\
\hline & & $6 \mathrm{~min}$ & $>1000$ & $>1000$ & 384 & 2.045 \\
\hline & & $9 \min$ & $>1000$ & $>1000$ & 396 & 2.707 \\
\hline \multirow{8}{*}{ C. pentandra } & & & $>1000$ & $>1000$ & 656 & 2.040 \\
\hline & & & $>1000$ & $>1000$ & 372 & 1.296 \\
\hline & & $3 \mathrm{~min}$ & $>1000$ & $>1000$ & 495 & 1.512 \\
\hline & MAE & $6 \mathrm{~min}$ & $>1000$ & $>1000$ & 624 & 1.661 \\
\hline & & $9 \mathrm{~min}$ & $>1000$ & $>1000$ & 544 & 1.112 \\
\hline & & $3 \mathrm{~min}$ & $>1000$ & $>1000$ & 544 & 1.203 \\
\hline & UAE & $6 \mathrm{~min}$ & $>1000$ & $>1000$ & 368 & 1.816 \\
\hline & & $9 \min$ & $>1000$ & $>1000$ & 512 & 1.640 \\
\hline & & & $>1000$ & $>1000$ & 190 & 2.181 \\
\hline & & & 944 & $>1000$ & 115.5 & 2.253 \\
\hline & & $3 \mathrm{~min}$ & $>1000$ & $>1000$ & 140 & 1.533 \\
\hline & MAE & $6 \mathrm{~min}$ & $>1000$ & $>1000$ & 160 & 1.587 \\
\hline 1. ammı & & $9 \mathrm{~min}$ & $>1000$ & $>1000$ & 145 & 1.547 \\
\hline & & $3 \mathrm{~min}$ & $>1000$ & $>1000$ & 136.5 & 1.605 \\
\hline & UAE & $6 \mathrm{~min}$ & $>1000$ & 592 & 126 & 1.736 \\
\hline & & $9 \mathrm{~min}$ & $>1000$ & 672 & 70 & 1.835 \\
\hline & & & $>1000$ & $>1000$ & 201 & 0.824 \\
\hline & & & $>1000$ & $>1000$ & 216 & 0.813 \\
\hline & & $3 \mathrm{~min}$ & $>1000$ & $>1000$ & 428 & 0.720 \\
\hline & MAE & $6 \mathrm{~min}$ & $>1000$ & $>1000$ & 284 & 0.723 \\
\hline 1. ғоепит-graесит & & $9 \min$ & $>1000$ & $>1000$ & 450 & 0.824 \\
\hline & & $3 \mathrm{~min}$ & $>1000$ & 626 & 365 & 1.187 \\
\hline & UAE & $6 \mathrm{~min}$ & $>1000$ & 496 & 426 & 0.912 \\
\hline & & $9 \min$ & $>1000$ & $>1000$ & 448 & 0.819 \\
\hline
\end{tabular}

\section{Conclusion}

On the basis of the obtained results, it can be concluded that fruit seeds are not waste to be discarded into the environment but they are of some worth and can be therapeutically exploited. They are enriched with phytoconstituents like phenols and flavonoids and hence can be used as a natural source of antioxidants. However, their extractability depends on extraction techniques and extraction solvents and in the present work, modern extraction techniques especially UAE proved best. Antioxidant activity was poor being water extracts and hence extraction by using other organic solvents is desirable. Work in this direction is in progress.

\section{Acknowledgement}

Department of Biosciences (UGC-CAS), Saurashtra University is gratefully acknowledged for excellent research facilities.

\section{References}

1. Sen K, Goel A, Rawal S, Mahajan N, Baboo S, Alok S. Antimicrobial activity of Basella rubra leaves. International Journal of Pharmaceutical Sciences and Research. 2010; 1(2):88-91.

2. Mirabella N, Castellani V, Sala S. Current options for the valorization of food manufacturing waste: A review. Journal of Cleaner Production. 2014; 65:28-41.

3. Rakholiya K, Kaneria M, Chanda S. Inhibition of microbial pathogens using fruit and vegetable peel extracts. International Journal of Food Science and Nutrition. 2014; 65(6):733-739.

4. Lee JJ, Saiful YL, Kassim NK, Che Abdullah CA, Esa N, Lim PC et al. Cytotoxic activity of Christia vespertilionis root and leaf extracts and fractions against breast cancer 
cell lines. Molecules, 2020, 25: doi:10.3390/ molecules25112610.

5. Alok S, Jain SK, Verma A, Kumar M, Mahor A, Sabharwal M.. Herbal antioxidant in clinical practice: A review. Asian Pacific Journal of Tropical Biomedicine. 2014; 4(1):78-84.

6. Chanda S, Rakholiya K, Parekh J. Indian medicinal herb: Antimicrobial efficacy of Mesua ferrea L. seed extracted in different solvents against infection causing pathogenic strains. Journal of Acute Disease. 2013; 2(4):277-281.

7. Loizzo MR, Pacetti D, Lucci P, Nunez O, Menichini F, Frega NG et al. Prunus persica var. platycarpa (Tabacchiera Peach): Bioactive compounds and antioxidant activity of pulp, peel and seed ethanolic extracts. Plant Foods for Human Nutrition. 2015; 70(3):331-337.

8. Wahid S, Khan RA, Zeeshan F, Ikram R. Analgesic, antiinflammatory and toxic effects of ethanol extracts of Cucumis melo and Citrullus lanatus seeds. Pakistan Journal of Pharmaceutical Sciences. 2020; 33:1049-1055.

9. Vu HT, Scarlett CJ, Vuong QV. Optimization of ultrasound-assisted extraction conditions for recovery of phenolic compounds and antioxidant capacity from banana (Musa cavendish) peel. Journal of Food Processing and Preservation. 2017; 41:e13148.

10. Donga S, Moteriya P, Chanda S. Evaluation of antimicrobial and synergistic antimicrobial properties of Pterocarpus santalinus. Asian Journal of Pharmaceutical and Clinical Research. 2017; 10(11):204-209.

11. Ekasari W, Wahyuni TS, Arwaty H, Putri NT. Determination of effective dose of antimalarial from Cassia spectabilis leaf ethanol extract in plasmodium berghei-infected mice. African Journal of Infectious Diseases. 2018; 12(1S):110-115.

12. Artanti N, Maryani F, Dewi RT, Handayani S, Dewijanti ID, Meilawati L et al. In vitro antidiabetic, antioxidant and cytotoxic activities of Syzygium cumini fractions from leaves ethanol extract. Indonesian Journal of Cancer Chemoprevention. 2019; 10(1): 24-29.

13. Baby MS, Antony AV, John B, Jose D. Phytochemical screening and in vitro anti-inflamatory activity of ethanolic extract of Centella asiatica. World Journal of Current Medical and Pharmaceutical Research. 2020; 2(2):181-183.

14. Zhang QW, Lin LG, Ye WC. Techniques for extraction and isolation of natural products: a comprehensive review. Chinese Medicine. 2018; 13(1):20. https://doi.org/10.1186/ s13020-018-0177-x.

15. Kothari V, Seshadri S. Antioxidant activity of seed extracts of Annona squamosa and Carica papaya. Nutrition \& Food Science. 2010; 40(4):doi:10.1108/00346651011062050.

16. Gupta SP, Singh MR, Ahemad I. Evaluation of antimicrobial activity of seed extracts of Annona squamosa L. and Azadirachta indica. Journal of Medicinal Plants. 2019; 7(4):282-284.

17. Jaiswal P, Singh DK. Molluscicidal activity of Carica papaya and Areca catechu against the freshwater snail Lymnaea acuminata. Veterinary Parasitology. 2008; 152:264-270.

18. Ang YK, Sia WC, Khoo HE, Yim HS. Antioxidant potential of Carica papaya peel and seed. Focusing on Modern Food Industry. 2012; 1(1):11-16.

19. Loganayaki N, Siddhuraju P, Manian S. Antioxidant activity and free radical scavenging capacity of phenolic extracts from Helicteres isora L. and Ceiba pentandra L.
Journal of Food Science and Technology. 2013; 50(4):687-695.

20. Ravi Kiran C, Raghava RT. Lipid profiling by GC-MS and anti-inflammatory activities of Ceiba pentandra seed oil. Journal of Biologically Active Products from Nature. 2014; 4(1):62-70.

21. Ramya N, Priyadharshini, Prakash R, Dhivya R. Anti cancer activity of Trachyspermum ammi against MCF-7 cell lines mediates by p53 and Bcl-2 mRNA levels. The Journal of Phytopharmacology. 2017; 6(2):78-83.

22. Wahab AT, Ilyas Q, Farooq S, Javaid S, Ahmed S, Rahman AU et al. In-vitro and in-vivo anticandidal activity of Trachyspermum ammi (L.) sprague seeds ethanolic extract and thymol-containing hexanes fraction. Natural Product, 2020. Research; https://doi.org/10.1080/14786419.2020.1731738.

23. Norziah MH, Fezea FA, Bhat R, Ahmad M. Effect of extraction solvents on antioxidant and antimicrobial properties of fenugreek seeds (Trigonella foenumgraecum L.). International Food Research Journal. 2015; 22(3):1261-1271.

24. Jain PG, Patil PP, Patil SD, Patil SD, Surana SJ. Evaluation of the antiasthmatic activity of methanolic extract of Trigonella Foenum Graecum on experimental models of bronchial asthma. Journal of Drug Delivery and Therapeutics. 2020; 10(1):101-106.

25. Vongsak B, Sithisarn P, Mangmool S, Thongpraditchote S, Wongkrajang Y, Gritsanapan W. Maximizing total phenolics, total flavonoids contents and antioxidant activity of Moringa oleifera leaf extract by the appropriate extraction method. Industrial Crops and Products, 2013; 44:566-571.

26. Dahmoune F, Nayak B, Moussi K, Remini H, Madani K. Optimization of microwave-assisted extraction of polyphenols from Myrtus communis L. leaves. Food Chemistry. 2015; 166:585-595.

27. Chen F, Sun Y, Zhao G, Liao X, Wu J, Wang Z. Optimization of ultrasound assisted extraction of anthocyanins in red raspberries and identification of anthocyanins in extract using high-performance liquid chromatography-mass spectrometry. Ultrasonic Sonochemistry. 2007; 14(6):767-778.

28. Yoganandi J, Pande J, Donga S, Chanda S. Comparative evaluation of different extraction techniques on various phytoconstituents of Terminalia Crenulata Roth. Research Trends in Medicinal Plant Sciences. 2018; 3:121-149.

29. Mc Donald S, Prenzler PD, Autolovich M, Robards K. Phenolic content and antioxidant activity of olive extracts. Food Chemistry. 2001; 73(1):73-84.

30. Tomczyk M, Pleszczynska M, Wiater A. Variation in total polyphenolics contents of aerial parts of Potentilla species and their anticariogenic activity. Molecules. 2010; 15:4639-4651.

31. Boutennoun H, Boussouf L, Rawashdeh A, Al-Qaoud K, Abdelhafez $\mathrm{S}$, Kebieche $\mathrm{M}$ et al. In vitro cytotoxic and antioxidant activities of phenolic components of Algerian Achillea odorata leaves. Arabian Journal of Chemistry. 2017; 10(3):403-409.

32. Abdel-Hameed ESS. Total phenolic contents and free radicals scavenging activity of certain Egyptian Ficus species leaf samples. Food Chemistry. 2009; 114(4):1271-1277.

33. Zilic S, Sukalovic VHT, Dodig D, Maksimovic V, Maksimovic M, Basic Z. Antioxidant activity of small grain cereals caused by phenolics and lipid soluble 
antioxidants. Journal of Cereal Science. 2011; 54(3):417424.

34. Mc Cune L, Johns T. Antioxidant activity in medicinal plant associated with the symptoms of diabetes mellitus used by the indigenous people of the North American boreal forest. Journal of Ethanopharmacology. 2002; 82:197-205.

35. Robak J, Gryglewski RJ. Flavonoids are scavenger of superoxide anions. Biochemical Pharmacology. 1988; 37:837-841.

36. Re R, Pellegrini N, Proteggentle A, Pannala A, Yang M, Rice-Evans C. Antioxidant activity applying an improved ABTS radical cation decolourisation assay. Free Radical Biology \& Medicine. 1999; 26:1231-1237.

37. Benzie IF, Strain J. The ferric reducing ability of plasma (FRAP) as a measure of "Antioxidant power" The FRAP assay. Analytical Biochemistry. 1996; 239:70-76.

38. Kaneria MJ, Rakholiya KD, Marsonia LR, Dave RA, Golakiya BA. Nontargeted metabolomics approach to determine metabolites profile and antioxidant study of Tropical Almond (Terminalia catappa L.) fruit peels using GC-QTOF-MS and LC-QTOF-MS. Journal of Pharmaceutical and Biomedical Analysis. 2018; 160:415427.

39. Taddeo VA, Epifano F, Fiorito S, Genovese S. Comparison of different extraction methods and HPLC quantification of prenylated and unprenylated phenylpropanoids in raw Italian propolis. Journal of Pharmaceutical and Biomedical Analysis. 2016; 129:219223.

40. de Oliveira Reis JH, de Abreu Barreto G, Cerqueira JC, dos Anjos JP, Andrade LN, Padilha FF et al. Evaluation of the antioxidant profile and cytotoxic activity of red propolis extracts from different regions of northeastern Brazil obtained by conventional and ultrasound-assisted extraction. Plos one. 2019; 14(7):https://doi.org/10.1371/journal.pone.0219063.

41. Pan X, Niu G, Liu H. Comparison of microwave-assisted extraction and conventional extraction techniques for the extraction of tanshinones from Salvia miltiorrhiza bunge. Biochemical Engineering Journal. 2002; 12(1):71-77.

42. Dadi DW, Emire SA, Hagos AD, Eun JB. Effect of ultrasound-assisted extraction of Moringa stenopetala leaves on bioactive compounds and their antioxidant activity. Food Technology and Biotechnology, 2019; 57(1):77-86.

43. Das S, Ray A, Nasim N, Nayak S, Mohanty S. Effect of different extraction techniques on total phenolic and flavonoid contents and antioxidant activity of betelvine and quantification of its phenolic constituents by validated HPTLC method. 3 Biotech. 2019; 9(1):37.

44. Rasheed DM, Porzel A, Frolov A, El Seedi HR, Wessjohann LA, Farag MA. Comparative analysis of Hibiscus sabdariffa (roselle) hot and cold extracts in respect to their potential for $\alpha$-glucosidase inhibition. Food Chemistry. 2018; 250:236-244.

45. Anaya-Esparza LM, Ramos-Aguirre D, Zamora-Gasga VM, Yahia E, Montalvo-Gonzalez E. Optimization of ultrasonic-assisted extraction of phenolic compounds from Justicia spicigera leaves. The Food Science and Biotechnology. 2018; 27(4):1093-1102.

46. Saini A, Panesar PS, Bera MB. Comparative study on the extraction and quantification of polyphenols from citrus peels using maceration and ultrasonic technique. Current
Research in Nutrition and Food Science. 2019; 7(3):678685.

47. Aguilar-Hernandez G, Garcia-Magana MD, Vivar-Vera MD, Sayago-Ayerdi SG, Sanchez-Burgos JA, MoralesCastro $\mathrm{J}$ et al. Optimization of ultrasound-assisted extraction of phenolic compounds from Annona muricata by-products and pulp. Molecules. 2019; 24(5):904. doi:10.3390/molecules24050904.

48. Ghafoor K, Choi YH, Jeon JY, Jo IH. Optimization of ultrasound-assisted extraction of phenolic compounds, antioxidants and anthocyanins from grape (Vitis vinifera) seeds. Journal of Agricultural and Food Chemistry. 2009; 57: 4988e4994.

49. Ge Zu, Rongrui Zhang, Lei Yang, Chunhui Ma, Yuangang $\mathrm{Zu}$, Wenjie Wang. Ultrasound-assisted extraction of carnosic acid and rosmarinic acid using ionic liquid solution from Rosmarinus officinalis. International Journal of Molecular Sciences. 2012; 13:11027-11043.

50. Li HZ Tan YL, Zhang ZJ, Xia YY, Li XJ, Cui LX, Chen T. Optimization of ultrasound-assisted extraction of procyanidins from perilla seed hull and their antioxidant activities in vitro. Food Science and Technology. 2019; 39(2):378-387.

51. Klavins L, Kviesis J, Nakurte I, Klavins M. Berry press residues as a valuable source of polyphenolics: Extraction optimisation and analysis. LWT- Food Science and Technology. 2018; 93:583-591.

52. Ramasamy J, Kandasamy R, Palanisamy S, Nadesan S. Optimization of ultrasonic-assisted extraction of flavonoids and anti-oxidant capacity from the whole plant of Andrographis echioides (L.) nees by response surface methodology and chemical composition analysis. Pharmacognosy Magazine. 2019; 15(65):547-556.

53. Chen H. Optimization of microwave-assisted extraction of resveratrol from Polygonum cuspidatum sieb et Zucc by orthogonal experiment. Natural Products: An Indian Journal. 2013; 9(4):138-142.

54. Xiong $\mathrm{W}$, Chen $\mathrm{X}, \mathrm{Lv} \mathrm{G}, \mathrm{Hu} \mathrm{D}$, Zhao J, Li S. Optimization of microwave assisted extraction of bioactive alkaloids from lotus plumule using response surface methodology. Journal of Pharmaceutical Analysis. 2016; 6(6):382-388.

55. Mihiretu GT, Brodin M, Chimphango AF, Oyaas K, Hoff BH, Gorgens JF. Single-step microwave-assisted hot water extraction of hemicelluloses from selected lignocellulosic materials - A biorefinery approach. Bioresource Technology. 2017; 241:669-680.

56. Nguyen MP. Mircowave-assisted extraction of phytochemical constituents in roselle (Hibiscus sabdariffa L.). Journal of Pharmaceutical Research International. 2020; 32(2):1-12.

57. Milani G, Curci F, Cavalluzzi MM, Crupi P, Pisano I, Lentini $\mathrm{G}$ et al. Optimization of microwave-assisted extraction of antioxidants from bamboo shoots of Phyllostachys pubescens. Molecules. 2020; 25(1):215. doi:10.3390/molecules25010215.

58. Li Y, Li S, Lin SJ, Zhang JJ, Zhao CN, Li HB. Microwave-assisted extraction of natural antioxidants from the exotic Gordonia axillaris fruit: Optimization and identification of phenolic compounds. Molecules. 2017; 22(9):1481. doi:10.3390/molecules22091481.

59. Da Porto C, Natolino A. Extraction kinetic modelling of total polyphenols and total anthocyanins from saffron 
floral bio-residues: Comparison of extraction methods. Food Chemistry. 2018; 258:137-143.

60. Savic IM, Gajic IM. Optimization of ultrasound-assisted extraction of polyphenols from wheatgrass (Triticum aestivum L.). Journal of Food Science and Technology. 2020; 57(8):2809-2818.

61. Aydar AY, Bagdathiglu N, Koseoglu O. Effect on olive oil extraction and optimization of ultra sound assisted extraction of extra virgin olive oil by response surface methodology (RSM). Grasas y Aceites. 2017; 68(2):doi: http://dx.doi.org/10.3989/ gya.1057162.

62. Bravo L, Goya L, Lecumberri E. LC/MS characterization of phenolic constituents of mate (Ilex paraguariensis, St. Hil.) and its antioxidant activity compared to commonly consumed beverages. Food Research International. 2007; 40(3):393-405.

63. Al-Huqail AA, Behiry SI, Salem MZ, Ali HM, Siddiqui $\mathrm{MH}$, Salem AZ. Antifungal, antibacterial and antioxidant activities of Acacia saligna (Labill.) HL Wendl. flower extract: HPLC analysis of phenolic and flavonoid compounds. Molecules. 2019; 24(4):700. doi:10.3390/molecules24040700.

64. Tohma H, Koksal E, Kilic O, Alan Y, Yılmaz MA, Gulcin I et al. RP-HPLC/MS/MS analysis of the phenolic compounds, antioxidant and antimicrobial activities of Salvia L. Species. Antioxidants. 2016; 5(4):38. doi:10.3390/antiox5040038.

65. Vu HT, Scarlett CJ, Vuong QV. Maximising recovery of phenolic compounds and antioxidant properties from banana peel using microwave assisted extraction and water. Journal of Food Science and Technology. 2019; 56(3):1360-1370, 